\title{
Clinical characteristics of patients with chronic obstructive pulmonary disease assessed using GOLD 2016 and GOLD 2018 classifications: a cross-sectional study in China
}

\author{
Wenhua Jian ${ }^{1} \wedge$, Huiqing Zeng ${ }^{2}$, Xiaoju Zhang ${ }^{3}$, Chunmei Yun ${ }^{4}$, Zuojun $\mathrm{Xu}^{5}$, Yan $\mathrm{Chen}^{6}$, Guochao Shi ${ }^{7}$, \\ Yingyu Wang ${ }^{8}$, Yun $\mathrm{Li}^{8}$, Jinping Zheng ${ }^{1} \wedge$
}

${ }^{1}$ State Key Laboratory of Respiratory Disease, National Clinical Research Centre for Respiratory Disease, Guangzhou Institute of Respiratory Health, First Affiliated Hospital of Guangzhou Medical University, Guangzhou, China; ${ }^{2}$ Department of Respiratory Medicine, Zhongshan Hospital Xiamen University, Xiamen, China; ${ }^{3}$ Department of Pulmonary and Critical Care Medicine, Henan Provincial People's Hospital, Zhengzhou, China; ${ }^{4}$ Department of Pulmonary and Critical Care Medicine, Inner Mongolia Autonomous Region People's Hospital, Hohhot, China; ${ }^{5}$ Department of Respiratory and Critical Care Medicine, Peking Union Medical College Hospital, Peking Union Medical College and Chinese Academy of Medical Sciences, Beijing, China; 'Department of Respiratory and Critical Medicine, The Second Xiangya Hospital, Central South University, Changsha, China; ${ }^{7}$ Department of Pulmonary and Critical Care Medicine, Shanghai Rui Jin Hospital, School of Medicine, Shanghai Jiao Tong University, Shanghai, China; ${ }^{8}$ GlaxoSmithKline, Shanghai, China

Contributions: (I) Conception and design: W Jian, J Zheng; (II) Administrative support: None; (III) Provision of study materials or patients: None; (IV) Collection and assembly of data: W Jian, H Zeng, X Zhang, C Yun, Z Xu, Y Chen, G Shi, J Zheng; (V) Data analysis and interpretation: Y Wang, Y Li; (VI) Manuscript writing: All authors; (VII) Final approval of manuscript: All authors.

Correspondence to: Jinping Zheng. National Clinical Research Centre for Respiratory Disease, State Key Laboratory of Respiratory Disease, Guangzhou Institute of Respiratory Health, First Affiliated Hospital of Guangzhou Medical University, Guangzhou 510120, China. Email: jpzhenggy@163.com.

Background: In 2017, the Global Initiative for Chronic Obstructive Lung Disease (GOLD) removed spirometry as a criterion for classifying GOLD risk groups (A-D, low-high risk).

Methods: In this cross-sectional observational study in China, we used the GOLD 2016 (spirometry included) and 2018 (spirometry eliminated) criteria for classifying GOLD risk groups to describe: the proportion of patients with chronic obstructive pulmonary disease (COPD) in each GOLD risk group; disease severity; demographics and comorbidities. Patients aged $\geq 40$ years with a clinical COPD diagnosis for $\geq 1$ year were included. During a single study visit, patients completed the COPD assessment test, modified Medical Research Council (mMRC) dyspnea scale assessment, and spirometry tests. Demographics, medical history, and treatment data were recorded.

Results: In total, 838 patients were included. Most patients were male (86.4\%), $\geq 65$ years old (58.6\%), and current or former smokers (78.5\%). By GOLD 2016, the highest proportion of patients were Group D (42.8\%), followed by B (28.2\%). By GOLD 2018, the highest proportion of patients were Group B (57.3\%), followed by A (25.5\%). A total of 296 patients (35.3\%) were reclassified, either from Group C to Group A or from Group D to Group B. Overall, 36.2\% of patients were receiving treatment concordant with GOLD 2016 recommendations; $34.1 \%$ were not receiving any inhaled medication.

Conclusions: The distribution of COPD severity shifted from a high-risk category (by GOLD 2016) to a low-risk category (by GOLD 2018). The high proportion of patients not receiving maintenance medication reflects a high level of under-treatment of the disease.

Keywords: China; chronic obstructive pulmonary disease (COPD); cross-sectional observational study; Global Initiative for Chronic Obstructive Lung Disease (GOLD) classification; dyspnea-scale assessment

^ ORCID: Wenhua Jian, 0000-0002-4012-9621; Chunmei Yun, 0000-0002-7853-6492; Jinping Zheng, 0000-0002-7511-661X. 
Submitted Feb 08, 2021. Accepted for publication Jul 19, 2021.

doi: $10.21037 /$ jtd-21-255

View this article at: https://dx.doi.org/10.21037/jtd-21-255

\section{Introduction}

Chronic obstructive pulmonary disease (COPD) is a common, preventable and treatable disease that is characterized by persistent respiratory symptoms and airflow limitation, and is commonly associated with comorbidity (1). The 2017 Global Burden of Disease Study (2) found that COPD was the seventh leading cause of death in the world. COPD is also associated with substantial economic and social burden (1). In a nationwide study in China from 2014 to 2015 , the estimated overall prevalence of COPD was $13.6 \%$ among adults aged $\geq 40$ years (3); furthermore, in China, COPD was the fifth leading cause of years of life lost according to a survey from 1980 to 2013 (4), indicating that COPD is a major public health problem. Although there is a high prevalence of COPD in China, little is known about the distribution of patients in terms of characteristics, disease severity, and treatments.

Patients with COPD have traditionally been categorized based on airflow limitation [assessed by forced expiratory volume in 1 second $\left(\mathrm{FEV}_{1}\right)$ measurement] (5). In 2011, the Global Initiative for Chronic Obstructive Lung Disease (GOLD) introduced a new classification system that recommended patients with COPD should be classified based on a combination of symptomatic assessment, using either a dyspnea measure [modified Medical Research Council (mMRC) dyspnea scale] or a health status measure [COPD Assessment Test (CAT) score], in addition to spirometry and/or risk of exacerbations $(6,7)$. With this system, patients with COPD are classified into four groups: Group A (low risk, fewer symptoms), Group B (low risk, more symptoms), Group C (high risk, fewer symptoms), and Group D (high risk, more symptoms). The GOLD strategy document is updated annually. In the 2017 revision, the degree of airflow limitation (based on spirometry classification) was eliminated from the ABCD categorization system: the GOLD 2017 update recommended the classification of patients into the four groups based only on symptomatic assessment and COPD exacerbation history (8). Subsequent updates to the GOLD guidelines maintained this method of categorization of severity, excluding spirometry measurements. Little is known about the impact of this change in criteria from GOLD 2016 to
2017 on the management of COPD.

In the present study, we used the GOLD 2016 classification criteria (9) (spirometry classification included) and GOLD 2018 classification criteria (10) (spirometry classification eliminated) to describe the proportion of patients with COPD in Groups A to D in a Chinese cohort. Additionally, we aimed to describe patients with COPD in terms of their demographic characteristics, disease severity (CAT score, exacerbation status, spirometry outcomes), COPD treatments and comorbidities in the overall population, and by GOLD 2016 and GOLD 2018 classifications.

We present the following article in accordance with the STROBE reporting checklist (available at https://dx.doi. org/10.21037/jtd-21-255).

\section{Methods}

\section{Patients}

The study population comprised patients with COPD seen during routine follow-up in outpatient clinics of tertiary hospitals (the largest and most sophisticated of the threelevel hospital system). The hospitals used as study sites were selected through expert discussion with the aim of achieving geographic and socio-demographic diversity representative of the whole of China.

Eligible patients were men or women aged $\geq 40$ years with a clinical diagnosis of COPD for $\geq 1$ year, with stable disease at enrollment. A clinical diagnosis of COPD was defined as dyspnea, chronic cough or sputum production, a history of exposure to COPD risk factors, and a postbronchodilator $\mathrm{FEV}_{1}$ to forced vital capacity (FVC) ratio $\left(\mathrm{FEV}_{1} / \mathrm{FVC}\right)$ of $<0.7$. Additionally, eligible patients were required to be outpatients; to be able to read, comprehend, and record information in Chinese; and to have provided written informed consent prior to study participation.

Patients were excluded from the study if they had any of the following at screening: a medical diagnosis of active tuberculosis, cystic fibrosis, lung cancer, hyper-eosinophilic syndrome, or any other pulmonary condition; or current participation in another COPD clinical study. Patients were also excluded if they had exacerbations within the preceding 
month, or any other unstable disease that could influence CAT or spirometry results. Thus, only patients with stable COPD were included and therefore use of maintenance medication could be accurately observed.

\section{Etbical statement}

Ethical approval and written informed consent was obtained for all participants. This study was conducted in accordance with the Declaration of Helsinki (as revised in 2013) and Good Clinical Practice. The study was approved by the Ethics Committee of scientific research project review in the First Affiliated Hospital of Guangzhou Medical University (approval No. 2018 K-19).

\section{Study design}

This multicenter, cross-sectional, observational, descriptive study was conducted at outpatient COPD clinics in eight tertiary hospitals across China between May 2017 and December 2018. The study included only one visit, during which all patients completed the CAT, and mMRC dyspnea assessment, and investigators collected data on demographics, exacerbations, blood eosinophil level, medical history, and current COPD treatments. Information was acquired from patient medical records; any information not available in medical records was acquired through patient recall (the type and amount of data collected through patient recall varied depending on the study site and the completeness of the patient's medical record). This was with the exception of spirometry data, which were either collected during the study visit or from the most recent data (within 6 months of study visit) in the patient's medical record. Patients were considered to have completed the study once the above data were collected; there was no follow-up for this study. After the study, management of patients, including their prescribed medications, continued to be at the physician's discretion.

\section{Endpoints}

The primary endpoints were the proportion of patients classified according to GOLD 2016 and GOLD 2018 $\mathrm{ABCD}$ groups; and the recording and evaluation of demographic characteristics [including gender, age, body mass index (BMI), waistline measurement, and smoking status], disease severity (based on CAT score, exacerbation status, mMRC dyspnea score, and spirometry), and comorbidities (determined from medical records and/or patient recall). The secondary endpoint was the proportion of patients in each GOLD 2016 group currently treated in concordance with the first or alternative treatments recommended.

\section{Assessments}

In order to categorize patients into $\mathrm{ABCD}$ groups according to the GOLD 2016 classification system, patients' symptoms, exacerbation risk and spirometry measurements were evaluated. The same approach was used to categorize patients according to the GOLD 2018 classification system, except that spirometry measurements were not included as part of the assessment (Figure S1). First, symptoms were evaluated based on the CAT score and categorized per severity (fewer symptoms: CAT score $<10$; more symptoms: CAT score $\geq 10$ ). Exacerbation risk was then determined based on exacerbation history, assessed by the number of exacerbations within the previous 12 months: low risk: 0 or 1 exacerbation; high risk: $\geq 2$ exacerbations or $\geq 1$ exacerbation requiring hospitalization. Lastly, to classify patients by GOLD 2016, spirometry was used to determine the grade of airflow limitation. The most recent spirometry data available, collected either during the study visit or within 6 months prior to study visit, were documented. The severity of airflow limitation was categorized based on post-salbutamol $\mathrm{FEV}_{1}$ : GOLD 1 (mild): $\mathrm{FEV}_{1} \geq 80 \%$ predicted; GOLD 2 (moderate): $50 \% \leq \mathrm{FEV}_{1}<80 \%$ predicted; GOLD 3 (severe): $30 \% \leq \mathrm{FEV}_{1}<50 \%$ predicted; and GOLD 4 (very severe): $\mathrm{FEV}_{1}<30 \%$ predicted. GOLD 1 and 2 were considered low risk, and GOLD 3 and 4 were considered high risk.

\section{Statistical analyses}

Data were analyzed descriptively only. Continuous data were expressed as mean and standard deviation (SD) and categorical data were summarized using frequency counts and percentages. The analysis set was all eligible patients who participated in this study.

\section{Results}

\section{Study population}

Of the 948 patients enrolled, 838 met the eligibility criteria and were included in the analyses (Figure 1). Patients who were screen failures $(\mathrm{n}=100)$ or had protocol deviations $(\mathrm{n}=10)$ 


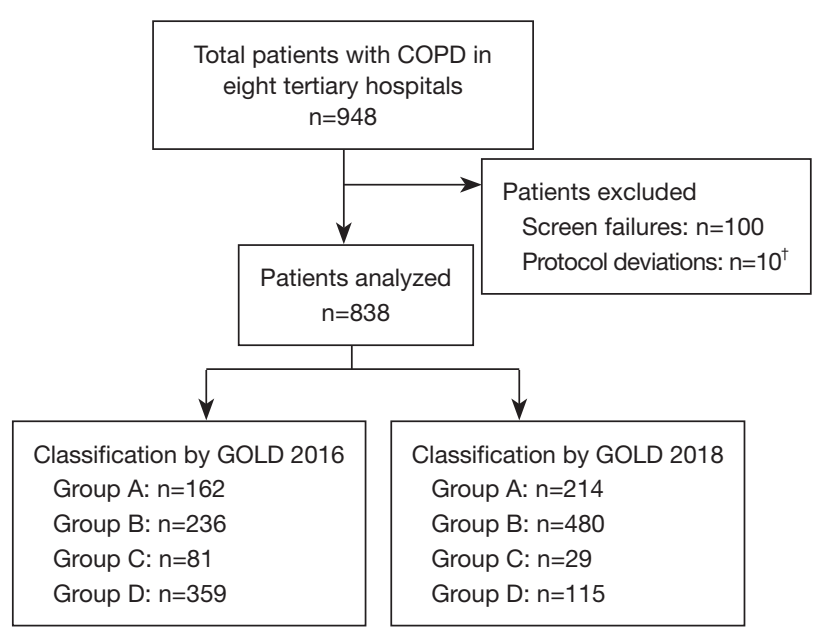

Figure 1 Patient disposition. ${ }^{\dagger}$, all protocol deviations were due to failure to meet eligibility criteria. COPD, chronic obstructive pulmonary disease; GOLD, Global Initiative for Chronic Obstructive Lung Disease.

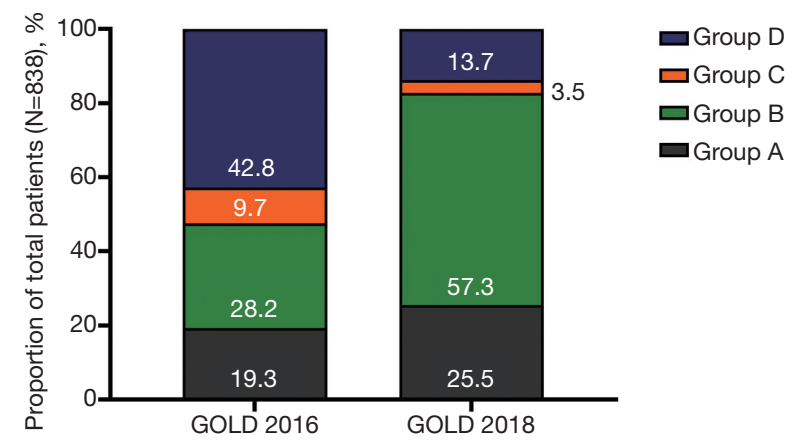

Figure 2 Proportion of patients classified by GOLD 2016 and GOLD 2018 ( $\mathrm{N}=838)$. GOLD, Global Initiative for Chronic Obstructive Lung Disease.

were excluded. All protocol deviations were due to failure to meet eligibility criteria. By GOLD 2016 classification, the highest proportion of patients were Group D [42.8\% $(\mathrm{n}=359)]$, followed by B [28.2\% $(\mathrm{n}=236)$ ]. By GOLD 2018 classification, the highest proportion of patients were Group B [57.3\% ( $\mathrm{n}=480)]$, followed by A [25.5\% $(\mathrm{n}=214)]$ (Figure 2, Table 1). Cohen's K-coefficient was calculated to assist the evaluation of the agreement between the two GOLD criteria, and was determined to be 0.5143 .

\section{Demographic and clinical characteristics}

In the total study population ( $\mathrm{N}=838)$, mean (SD) age was
65.7 (8.6) years. The majority of patients were $\geq 65$ years of age [58.6\% $(n=491)]$, and were male [86.4\% $(n=724)]$ (Table 1). There were no marked differences among Groups A-D with respect to patient age by either GOLD 2016 or GOLD 2018 classifications. Most patients [78.5\% (n=658)] were former or current smokers and the mean number of pack years was 39.1. Patients in Group D by both GOLD 2016 and GOLD 2018 classifications had the highest mean (SD) number of pack years [GOLD 2016 Group D: 41.4 (27.9); GOLD 2018 Group D: 45.1 (31.4)]. Patients in Group C by GOLD 2016 and Group A by GOLD 2018 classifications had the lowest number of pack-years: 34.6 (22.5) and 35.0 (22.3), respectively. The mean (SD) BMI of the total population was $23.1(3.6) \mathrm{kg} / \mathrm{m}^{2}$ and the mean (SD) waistline measurement was $86.5(10.3) \mathrm{cm}$.

The majority of patients in the total population had moderate-to-severe airflow limitation [GOLD 2: 44.5\% $(\mathrm{n}=373)$; GOLD 3: 32.8\% $(\mathrm{n}=275)]$. Overall, $71.0 \%(\mathrm{n}=595)$ of patients had a CAT score $\geq 10$, meaning that they were classified into Groups B or D according to both GOLD 2016 and 2018 classifications. Figure 3 shows the proportion of patients with each GOLD spirometry classification (GOLD 1-4) according to GOLD 2016 and GOLD 2018 ABCD groups. However, GOLD spirometry classification is not considered as a criterion for GOLD 2018 classification; this information is presented only for comparison between the classifications. Per GOLD 2018 versus GOLD 2016, respectively, fewer patients with GOLD 2 (moderate airflow limitation) were classed as Group A [57.5\% ( $\mathrm{n}=123)$ vs. $75.9 \%(\mathrm{n}=123)]$ and Group B [42.3\% $(\mathrm{n}=203)$ vs. $86.0 \%(\mathrm{n}=203)$ ]. Of patients with GOLD 3 (severe airflow limitation) a marked proportion were classed as Group A and B per GOLD 2018 classification $[23.4 \%(n=50)$ and $33.1 \%$ ( $n=159$ ), respectively] compared with GOLD 2016 classification, according to which no patients with GOLD 3 were classed as GOLD A or B.

For most patients, COPD had a mild-to-moderate impact on health status, with $29.0 \%(\mathrm{n}=243)$ of patients having CAT score $<10$ and $41.2 \%(n=345)$ with a CAT score of $10-<20$. The mean (SD) CAT score was 15.0 (8.0). In total, $25.1 \%(\mathrm{n}=210)$ of patients had experienced $\geq 1$ exacerbation in the preceding 12 months and $17.2 \%(n=144)$ of patients had experienced $\geq 1$ exacerbation requiring hospitalization or $\geq 2$ exacerbations. In comparison, $74.9 \%$ $(n=628)$ of the total patient population experienced no exacerbations in the preceding 12 months.

The mean (SD) eosinophil percentage and absolute eosinophil value of the overall population was $3.1(2.5)$ and 
Table 1 Patient demographics and clinical characteristics by GOLD 2016 and GOLD 2018 classification (N=838)

\begin{tabular}{|c|c|c|c|c|c|c|c|c|c|}
\hline Characteristic & Total & \multicolumn{4}{|c|}{ GOLD 2016} & \multicolumn{4}{|c|}{ GOLD 2018} \\
\hline n (\%) & $838(100.0)$ & $162(19.3)$ & $236(28.2)$ & $81(9.7)$ & $359(42.8)$ & $214(25.5)$ & $480(57.3)$ & $29(3.5)$ & $115(13.7)$ \\
\hline Age, years, mean (SD) & $65.7(8.6)$ & $64.7(9.4)$ & $66.1(8.6)$ & $65.3(8.5)$ & $65.9(8.1)$ & $64.6(9.1)$ & $65.7(8.3)$ & $66.9(9.1)$ & $67.0(8.5)$ \\
\hline \multicolumn{10}{|l|}{ Age group, $\mathrm{n}(\%)$} \\
\hline$\geq 65$ years & $491(58.6)$ & $96(59.3)$ & $145(61.4)$ & $36(44.4)$ & $214(59.6)$ & $117(54.7)$ & $288(60.0)$ & $15(51.7)$ & $71(61.7)$ \\
\hline \multicolumn{10}{|l|}{ Gender, n (\%) } \\
\hline Male & $724(86.4)$ & $137(84.6)$ & $192(81.4)$ & $70(86.4)$ & $325(90.5)$ & $181(84.6)$ & $413(86.0)$ & $26(89.7)$ & $104(90.4)$ \\
\hline $\mathrm{BMI}, \mathrm{kg} / \mathrm{m}^{2}$, mean $(\mathrm{SD})$ & $23.1(3.6)$ & $24.3(3.3)$ & $24.2(3.5)$ & $22.6(3.6)$ & $21.9(3.5)$ & 23.8 (3.3) & $23.1(3.7)$ & $22.7(4.5)$ & $21.9(3.5)$ \\
\hline$<18.5$ & $78(9.3)$ & $6(3.7)$ & $9(3.8)$ & $8(9.9)$ & $55(15.3)$ & $10(4.7)$ & $44(9.2)$ & $4(13.8)$ & $20(17.4)$ \\
\hline $18.5-23.9$ & $434(51.9)$ & 76 (46.9) & $106(45.3)$ & $44(54.3)$ & $208(57.9)$ & $106(49.5)$ & $250(52.3)$ & $14(48.3)$ & $64(55.7)$ \\
\hline $24.0-27.9$ & $250(29.9)$ & $61(37.7)$ & $85(36.3)$ & $22(27.2)$ & $82(22.8)$ & $76(35.5)$ & $140(29.3)$ & 7 (24.1) & 27 (23.5) \\
\hline$\geq 28.0$ & 74 (8.9) & $19(11.7)$ & $34(14.5)$ & $7(8.6)$ & $14(3.9)$ & $22(10.3)$ & $44(9.2)$ & $4(13.8)$ & $4(3.5)$ \\
\hline Missing & $2(0.2)$ & 0 & $2(0.8)$ & 0 & 0 & 0 & $2(0.4)$ & 0 & 0 \\
\hline $\begin{array}{l}\text { Waistline measurement, } \mathrm{cm} \text {, } \\
\text { mean (SD) }\end{array}$ & $86.5(10.3)$ & $88.6(9.1)$ & $87.9(9.5)$ & $83.9(11.2)$ & $85.3(10.8)$ & $87.1(9.8)$ & $86.8(10.5)$ & $86.2(11.7)$ & $84.5(9.6)$ \\
\hline Missing, n (\%) & $4(0.5)$ & 0 & $4(1.7)$ & 0 & 0 & 0 & $4(0.8)$ & 0 & 0 \\
\hline $\mathrm{n}$ & 658 & 117 & 176 & 64 & 301 & 158 & 378 & 23 & 99 \\
\hline Mean (SD) & $39.1(25.8)$ & 35.4 (22.6) & 39.2 (24.9) & $34.6(22.5)$ & 41.4 (27.9) & $35.0(22.3)$ & 39.4 (25.4) & $36.1(24.4)$ & $45.1(31.4)$ \\
\hline \multicolumn{10}{|l|}{ mMRC dyspnea grade ${ }^{\ddagger}, \mathrm{n}(\%)$} \\
\hline 0 & $120(14.3)$ & $64(39.5)$ & $27(11.4)$ & $16(19.8)$ & $13(3.6)$ & $74(34.6)$ & $34(7.1)$ & $6(20.7)$ & $6(5.2)$ \\
\hline 1 & $316(37.7)$ & $80(49.4)$ & $97(41.1)$ & $38(46.9)$ & $101(28.1)$ & $107(50.0)$ & $173(36.0)$ & $11(37.9)$ & $25(21.7)$ \\
\hline 2 & $269(32.1)$ & $17(10.5)$ & $86(36.4)$ & $24(29.6)$ & $142(39.6)$ & $30(14.0)$ & $181(37.7)$ & $11(37.9)$ & $47(40.9)$ \\
\hline 3 & $120(14.3)$ & $1(0.6)$ & $23(9.7)$ & $3(3.7)$ & $93(25.9)$ & $3(1.4)$ & $84(17.5)$ & $1(3.4)$ & $32(27.8)$ \\
\hline 4 & $13(1.6)$ & 0 & $3(1.3)$ & 0 & $10(2.8)$ & 0 & $8(1.7)$ & 0 & $5(4.3)$ \\
\hline CAT total score, mean (SD) & $15.0(8.0)$ & $6.0(2.4)$ & $17.0(5.9)$ & $5.8(2.4)$ & $19.8(6.3)$ & $6.0(2.4)$ & $18.3(6.1)$ & $5.4(2.3)$ & $20.3(6.8)$ \\
\hline
\end{tabular}

Table 1 (continued) 
Table 1 (continued)

\begin{tabular}{|c|c|c|c|c|c|c|c|c|c|}
\hline Characteristic & Total & \multicolumn{4}{|c|}{ GOLD 2016} & \multicolumn{4}{|c|}{ GOLD 2018} \\
\hline \multicolumn{10}{|l|}{ CAT total score category, $\mathrm{n}(\%)$} \\
\hline $0-<10$ & $243(29.0)$ & $162(100.0)$ & 0 & $81(100.0)$ & 0 & $214(100.0)$ & 0 & $29(100.0)$ & 0 \\
\hline $10-<20$ & $345(41.2)$ & 0 & $167(70.8)$ & 0 & $178(49.6)$ & 0 & $289(60.2)$ & 0 & $56(48.7)$ \\
\hline $30-\leq 40$ & $29(3.5)$ & 0 & $8(3.4)$ & 0 & $21(5.8)$ & 0 & $19(4.0)$ & 0 & $10(8.7)$ \\
\hline \multicolumn{10}{|c|}{$\geq 1$ exacerbation in the last 12 months, $n(\%)$} \\
\hline Yes & $210(25.1)$ & $15(9.3)$ & $25(10.6)$ & $37(45.7)$ & $133(37.0)$ & $23(10.7)$ & $43(9.0)$ & $29(100.0)$ & $115(100.0)$ \\
\hline No & $628(74.9)$ & $147(90.7)$ & $211(89.4)$ & $44(54.3)$ & $226(63.0)$ & $191(89.3)$ & $437(91.0)$ & 0 & 0 \\
\hline $\begin{array}{l}1 \text { exacerbation (not } \\
\text { requiring hospitalization) }\end{array}$ & $64(7.6)$ & $15(9.3)$ & $24(10.2)$ & $8(9.9)$ & $17(4.7)$ & $23(10.7)$ & $41(8.6)$ & 0 & 0 \\
\hline $\begin{array}{l}\geq 1 \text { exacerbation requiring } \\
\text { hospitalization }\end{array}$ & $118(14.1)$ & 0 & 0 & $20(24.7)$ & $98(27.3)$ & 0 & 0 & $20(69.0)$ & $98(85.2)$ \\
\hline$\geq 2$ exacerbations & $46(5.5)$ & 0 & 0 & $12(14.8)$ & $34(9.5)$ & 0 & 0 & $12(41.4)$ & $34(29.6)$ \\
\hline $\begin{array}{l}\geq 1 \text { exacerbation requiring } \\
\text { hospitalization or } \\
\geq 2 \text { exacerbations }\end{array}$ & $144(17.2)$ & 0 & 0 & $29(35.8)$ & $115(32.0)$ & 0 & 0 & $29(100.0)$ & $115(100.0)$ \\
\hline \multicolumn{10}{|l|}{ Spirometry classification, $\mathrm{n}(\%)^{\dagger \dagger}$} \\
\hline $\mathrm{FEV}_{1} / \mathrm{FVC}$ ratio, mean (SD) & $0.49(0.1)$ & $0.58(0.1)$ & $0.56(0.1)$ & $0.44(0.1)$ & $0.41(0.1)$ & $0.54(0.1)$ & $0.48(0.1)$ & $0.49(0.1)$ & $0.44(0.1)$ \\
\hline $\mathrm{FEV}_{1} \%$ predicted, mean (SD) & $52.7(19.4)$ & 70.3 & $66.1(12.3)$ & $44.9(12.7)$ & $37.7(13.1)$ & $63.1(17.4)$ & $50.2(19.1)$ & $51.9(17.5)$ & $44.1(17.0)$ \\
\hline $\begin{array}{l}\text { Eosinophil percentage (\%), } \\
\text { mean (SD) }\end{array}$ & $3.1(2.5)$ & $3.2(2.8)$ & $3.2(2.7)$ & $2.9(1.9)$ & $3.1(2.5)$ & $3.1(2.6)$ & $3.1(2.6)$ & $3.1(1.8)$ & $3.1(2.3)$ \\
\hline \multicolumn{10}{|l|}{ Eosinophil percentage category } \\
\hline $0-<2 \%, n(\%)$ & $316(38.4)$ & $60(37.5)$ & $91(39.4)$ & $28(34.6)$ & $137(39.1)$ & $81(38.2)$ & $186(39.6)$ & $7(24.1)$ & $42(37.8)$ \\
\hline $2-<4 \%, n(\%)$ & 305 (37.1) & $60(37.5)$ & $80(34.6)$ & $33(40.7)$ & $132(37.7)$ & 78 (36.8) & $168(35.7)$ & $15(51.7)$ & $44(39.6)$ \\
\hline $4-<6 \%, n(\%)$ & $112(13.6)$ & $24(15.0)$ & $34(14.7)$ & $12(14.8)$ & $42(12.0)$ & $32(15.1)$ & $63(13.4)$ & $4(13.8)$ & $13(11.7)$ \\
\hline$\geq 6 \%, \mathrm{n}(\%)$ & $89(10.8)$ & $16(10.0)$ & $26(11.3)$ & $8(9.9)$ & $39(11.1)$ & $21(9.9)$ & $53(11.3)$ & $3(10.3)$ & $12(10.8)$ \\
\hline Missing, $\mathrm{n}$ & 16 & 2 & 5 & 0 & 9 & 2 & 10 & 0 & 4 \\
\hline
\end{tabular}

Table 1 (continued) 
Table 1 (continued)

\begin{tabular}{|c|c|c|c|c|c|c|c|c|c|}
\hline Characteristic & Total & \multicolumn{4}{|c|}{ GOLD 2016} & \multicolumn{4}{|c|}{ GOLD 2018} \\
\hline $\begin{array}{l}\text { Eosinophil absolute value, } \\
10^{9} / \mathrm{L} \text {, mean (SD) }\end{array}$ & $0.23(0.29)$ & $0.22(0.20)$ & $0.22(0.20)$ & $0.22(0.15)$ & $0.23(0.38)$ & $0.22(0.19)$ & $0.21(0.18)$ & $0.23(0.15)$ & $0.29(0.63)$ \\
\hline \multicolumn{10}{|c|}{ Eosinophil absolute value category } \\
\hline $100-<150$ cells $/ \mu \mathrm{L}, \mathrm{n}(\%)$ & $174(21.2)$ & $31(19.4)$ & $43(18.7)$ & $17(21.0)$ & $83(23.7)$ & $40(18.9)$ & $100(21.3)$ & $8(27.6)$ & $26(23.4)$ \\
\hline $150-<300$ cells $/ \mu \mathrm{L}, \mathrm{n}(\%)$ & $276(33.6)$ & $55(34.4)$ & $80(34.8)$ & $29(35.8)$ & $112(32.0)$ & $71(33.5)$ & $159(33.9)$ & $13(44.8)$ & $33(29.7)$ \\
\hline$\geq 300$ cells/ $/ \mu$, $n(\%)$ & $185(22.5)$ & $37(23.1)$ & $47(20.4)$ & $19(23.5)$ & $82(23.4)$ & $50(23.6)$ & $97(20.7)$ & $6(20.7)$ & $32(28.8)$ \\
\hline
\end{tabular}

${ }^{\dagger}$, pack-years $=$ number of packs per day $\times$ number of smoking years. ${ }^{\ddagger}$, grade 0 , breathless only with strenuous exercise; grade 1 , breathless when hurrying on the level or walking on a slight hill; grade 2, walks slower than people of the same age on the level because of breathlessness or has to stop when walking at own pace on the level; grade 3, stops for breath after walking $100 \mathrm{~m}$ or after a few minutes on the level; grade 4, too breathless to leave the house or breathless when dressing or undressing. ${ }^{\S}$, exacerbations in the last 12 months. ", data from two patients omitted due to inconsistencies in patient response. ${ }^{\dagger \dagger}$, GOLD 1: mild, FEV 1 (80\% predicted; GOLD 2: moderate, $50 \% \leq \mathrm{FEV}_{1}<80 \%$ predicted; GOLD 3: severe, $30 \% \leq \mathrm{FEV}_{1}<50 \%$ predicted; GOLD 4: very severe, $\mathrm{FEV}_{1}<30 \%$ predicted. BMI, body mass index; CAT, COPD Assessment Test; COPD, chronic obstructive pulmonary disease; $\mathrm{FEV}_{1}$, forced expiratory volume in 1 second; FVC, forced vital capacity; GOLD, Global Initiative for Chronic Obstructive Lung Disease; mMRC, modified Medical Research Council; SD, standard deviation.

0.23 (0.29), respectively. As per the eosinophil elevation cut-off criteria of $2 \%$, more than $40 \%$ of the patients from each group had elevated blood eosinophil levels, when classified according to both GOLD 2016 and GOLD 2018. Irrespective of the classification criteria applied to the patient population, approximately one-third of the patients from all groups (range, 29.7-44.8\%) had absolute blood eosinophil values in the range $150-<300$ cells $/ \mu \mathrm{L}$.

\section{Comorbidity}

In the total study population $(\mathrm{N}=838), 52.1 \%(\mathrm{n}=437)$ of patients had a comorbid condition (Table 2), the most common being hypertension [27.0\% $(\mathrm{n}=226)]$, followed by current asthma $[15.9 \%(\mathrm{n}=133)]$, allergic rhinitis $[11.8 \%$ $(\mathrm{n}=99)]$, diabetes $[7.4 \%(\mathrm{n}=62)]$, and hyperlipidemia $[7.2 \%$ $(n=60)]$. The proportions of patients with hypertension in each group varied depending on GOLD classification. Per GOLD 2016 classification, proportions were equally distributed across all four groups; however, per GOLD 2018 classification, hypertension was more common in patients in Groups C and D [37.9\% ( $\mathrm{n}=11)$ and $33.9 \%$ $(\mathrm{n}=39)$, respectively] compared with those in Groups A and
B [26.2\% $(\mathrm{n}=56)$ and $25.0 \%(\mathrm{n}=120)$, respectively]. On a descriptive level, there was no obvious association between the groups with high eosinophil counts (Table 1) and the groups with current asthma (Table 2).

\section{Changes in patient ABCD classification according to GOLD 2018 criteria}

Demographics and clinical characteristics for patients whose ABCD grouping changed in the reclassification from GOLD 2016 to GOLD 2018 are described in Table S1. The mean (SD) CAT score in all patients who were reclassified (either from Group C to Group A or from Group D to Group B, total $n=296$ ) was 17.1 (7.7). In the group of patients who were reclassified from Group C (as per GOLD 2016) to Group A (as per GOLD 2018), more patients were $<65$ years of age than $\geq 65$ years of age $[59.6 \%$ $(\mathrm{n}=31)$ vs. $40.4 \% \quad(\mathrm{n}=21)$, respectively]. The majority of patients who were reclassified from Group $\mathrm{C}$ to A had grade $1 \mathrm{mMRC}$ dyspnea [51.9\% ( $\mathrm{n}=27)]$, and the mean (SD) CAT score in patients who were reclassified from Group C to A $(\mathrm{n}=52)$ was $5.9(2.5)$. In patients who were reclassified from Group D (GOLD 2016) to Group B (GOLD 2018), more 


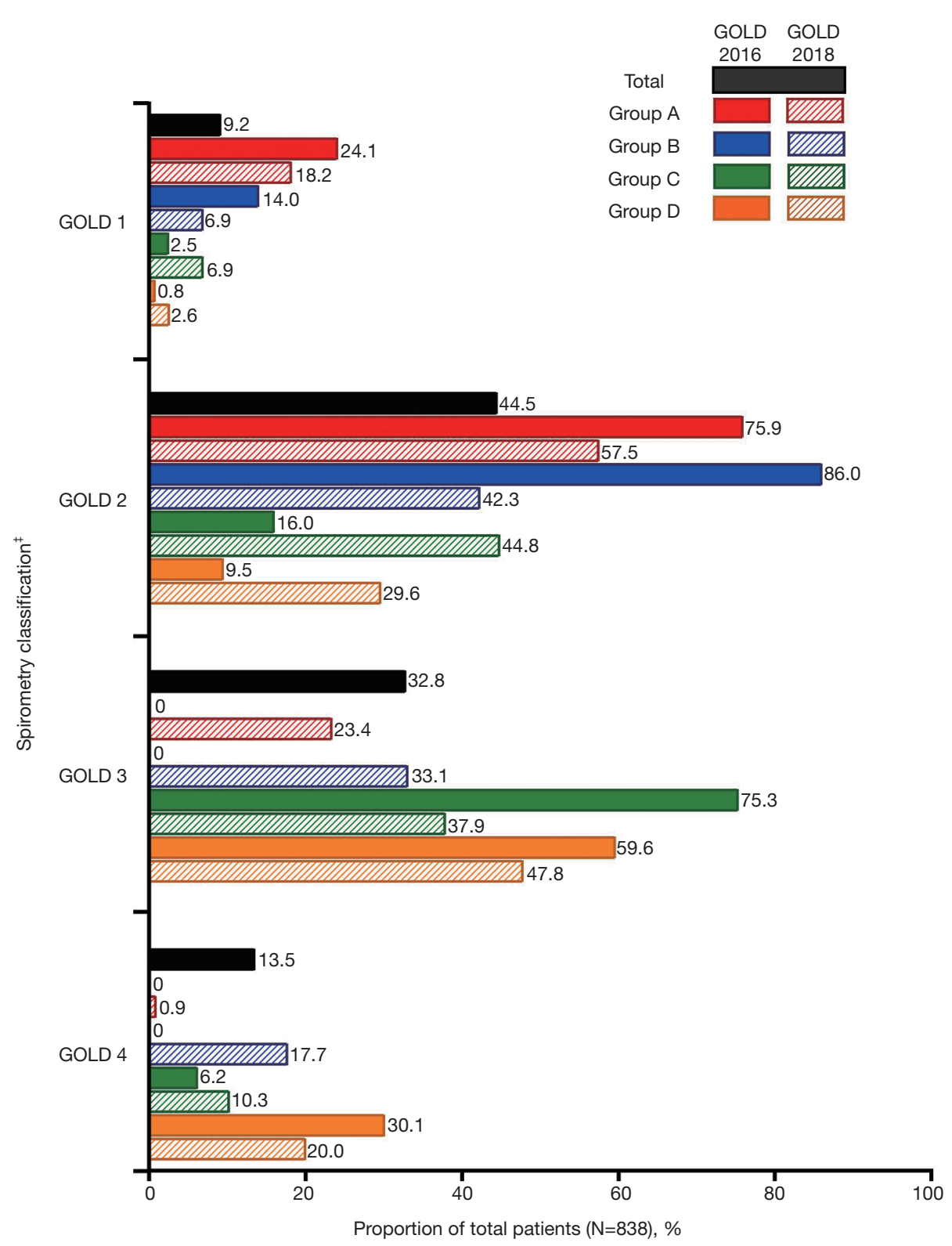

Figure 3 Proportion of patients in GOLD spirometry classifications ${ }^{\dagger}(\mathrm{N}=838) .{ }^{\dagger}$, GOLD spirometry classification is not considered as a criterion for GOLD 2018 classification; this information is presented only for comparison between the classifications. ${ }^{\ddagger}$, GOLD 1: mild, $\mathrm{FEV}_{1} \geq 80 \%$ predicted; GOLD 2: moderate, $50 \% \leq \mathrm{FEV}_{1}<80 \%$ predicted; GOLD 3: severe, 30\% $\leq$ FEV $<50 \%$ predicted; GOLD 4: very severe, $\mathrm{FEV}_{1}<30 \%$ predicted. $\mathrm{FEV}_{1}$, forced expiratory volume in 1 second; GOLD, Global Initiative for Chronic Obstructive Lung Disease.

patients were $\geq 65$ years of age than $<65$ years of age $[58.6 \%$ $(\mathrm{n}=143)$ vs. $41.4 \%(\mathrm{n}=101)$, respectively]. The majority of patients $[38.9 \%(n=95)]$ who were reclassified from Group D (GOLD 2016) to Group B (GOLD 2018) had grade 2 mMRC dyspnea. The mean (SD) CAT score of patients who were reclassified from Group D (GOLD 2016) to Group B (GOLD 2018) was 19.5 (6.1); 95.5\% (n=233) of patients in this category had CAT scores of $10-<30$. The majority of patients who were reclassified in both categories had no exacerbations in the preceding 12 months [Groups C to A reclassification: $84.6 \%(n=44)$; Group D to B reclassification: $93.0 \%(n=227)$ ]. All remaining patients experienced one exacerbation (not requiring hospitalization) in the preceding 12 months [Group C to A reclassification: 
Table 2 Comorbidities in patients according to GOLD 2016 and GOLD 2018 classification $(\mathrm{n}=838)$

\begin{tabular}{|c|c|c|c|c|c|c|c|c|c|}
\hline Comorbidity & Total & \multicolumn{4}{|c|}{ GOLD 2016} & \multicolumn{4}{|c|}{ GOLD 2018} \\
\hline Patients, n (\%) & $838(100.0)$ & $162(19.3)$ & $236(28.2)$ & $81(9.7)$ & $359(42.8)$ & $214(25.5)$ & $480(57.3)$ & $29(3.5)$ & $115(13.7)$ \\
\hline Comorbidities, n (\%) & $437(52.1)$ & $88(54.3)$ & $133(56.4)$ & $41(50.6)$ & $175(48.7)$ & $110(51.4)$ & $242(50.4)$ & $19(65.5)$ & $66(57.4)$ \\
\hline Hypertension & $226(27.0)$ & $44(27.2)$ & $66(28.0)$ & $23(28.4)$ & $93(25.9)$ & $56(26.2)$ & $120(25.0)$ & $11(37.9)$ & 39 (33.9) \\
\hline Allergic rhinitis & $99(11.8)$ & $24(14.8)$ & $37(15.7)$ & $5(6.2)$ & $33(9.2)$ & $27(12.6)$ & $59(12.3)$ & $2(6.9)$ & $11(9.6)$ \\
\hline Diabetes & $62(7.4)$ & $9(5.6)$ & $21(8.9)$ & $7(8.6)$ & $25(7.0)$ & $12(5.6)$ & $40(8.3)$ & $4(13.8)$ & $6(5.2)$ \\
\hline Hyperlipidemia & $60(7.2)$ & $20(12.3)$ & $15(6.4)$ & $5(6.2)$ & $20(5.6)$ & $24(11.2)$ & $28(5.8)$ & $1(3.4)$ & $7(6.1)$ \\
\hline Ischemic heart disease & $59(7.0)$ & $7(4.3)$ & $18(7.6)$ & $6(7.4)$ & $28(7.8)$ & $10(4.7)$ & $33(6.9)$ & $3(10.3)$ & $13(11.3)$ \\
\hline Heart failure & $10(1.2)$ & $1(0.6)$ & $1(0.4)$ & $0(0.0)$ & $8(2.2)$ & $1(0.5)$ & $6(1.3)$ & $0(0.0)$ & $3(2.6)$ \\
\hline Atrial fibrillation & $9(1.1)$ & $0(0.0)$ & $3(1.3)$ & $1(1.2)$ & $5(1.4)$ & $1(0.5)$ & $6(1.3)$ & $0(0.0)$ & $2(1.7)$ \\
\hline $\begin{array}{l}\text { Obstructive sleep apnea } \\
\text { syndrome }\end{array}$ & $8(1.0)$ & $0(0.0)$ & $2(0.8)$ & $4(4.9)$ & $2(0.6)$ & $1(0.5)$ & $2(0.4)$ & $3(10.3)$ & $2(1.7)$ \\
\hline Anxiety & $6(0.7)$ & $0(0.0)$ & $4(1.7)$ & $1(1.2)$ & $1(0.3)$ & $0(0.0)$ & $5(1.0)$ & $1(3.4)$ & $0(0.0)$ \\
\hline Depression & $5(0.6)$ & $1(0.6)$ & $2(0.8)$ & $0(0.0)$ & $2(0.6)$ & $1(0.5)$ & $4(0.8)$ & $0(0.0)$ & $0(0.0)$ \\
\hline
\end{tabular}

GOLD, Global Initiative for Chronic Obstructive Lung Disease.

15.4\% (n=8); Group D to B reclassification: 7.0\% ( $\mathrm{n}=17)]$. No patients in either category experienced $\geq 1$ exacerbation requiring hospitalization or $\geq 2$ exacerbations. Spirometry indicated that all reclassified patients had GOLD 3 or GOLD 4 severity, but this was only considered as a criterion for classification in the GOLD 2016 criteria.

\section{COPD inhaled medications}

In the total study population ( $\mathrm{N}=838)$, the most frequently prescribed therapy was inhaled corticosteroid (ICS) + longacting $\beta_{2}$-agonist (LABA) [27.6\% ( $\left.\mathrm{n}=231\right)$ ] followed by ICS + long-acting muscarinic antagonist (LAMA) + LABA [25.9\% $(\mathrm{n}=217)]$. Notably, $34.1 \%(\mathrm{n}=286)$ of patients were not receiving any inhaled medication for their COPD, representing a high level of under-treatment of COPD in this patient population. A higher proportion of patients received ICS + LAMA + LABA in Groups C and D per the GOLD 2016 classification $[38.3 \%(n=31)$ and $29.5 \%$ $(\mathrm{n}=106)$, respectively] compared with Groups C and D per the GOLD 2018 classification $[37.9 \%(\mathrm{n}=11)$ and $23.5 \%$ $(\mathrm{n}=27)$, respectively]. On the other hand, per GOLD 2018, a higher proportion of patients in Groups A and B received ICS + LAMA + LABA [25.7\% ( $n=55)$ and 25.8\% ( $n=124)$, respectively] compared with Groups A and B per GOLD 2016 classification $[21.6 \%(n=35)$ and $19.1 \%(n=45)$, respectively]. The proportion of patients in Group C who did not receive any COPD treatment was lower per GOLD 2018 classification $[3.4 \%(n=1)]$ compared with the GOLD 2016 classification [13.6\% $(\mathrm{n}=11)]$. All prescribed therapies are shown in Figure 4 and Table S2. Overall, 36.2\% (n=303) of patients were receiving COPD treatment concordant with GOLD 2016 recommendations: $32.8 \%(n=275)$ of patients were receiving the recommended first choice for COPD treatment, while $29.7 \%(\mathrm{n}=249)$ were receiving a recommended alternative choice (Figure 5, Table S2).

Details of patients who were managed on nonpharmacologic therapy for their COPD were also collected (data not shown). In total, $13.6 \%$ of patients $(n=114)$ were receiving oxygen therapy, most of whom $(12.2 \%$ of the total 


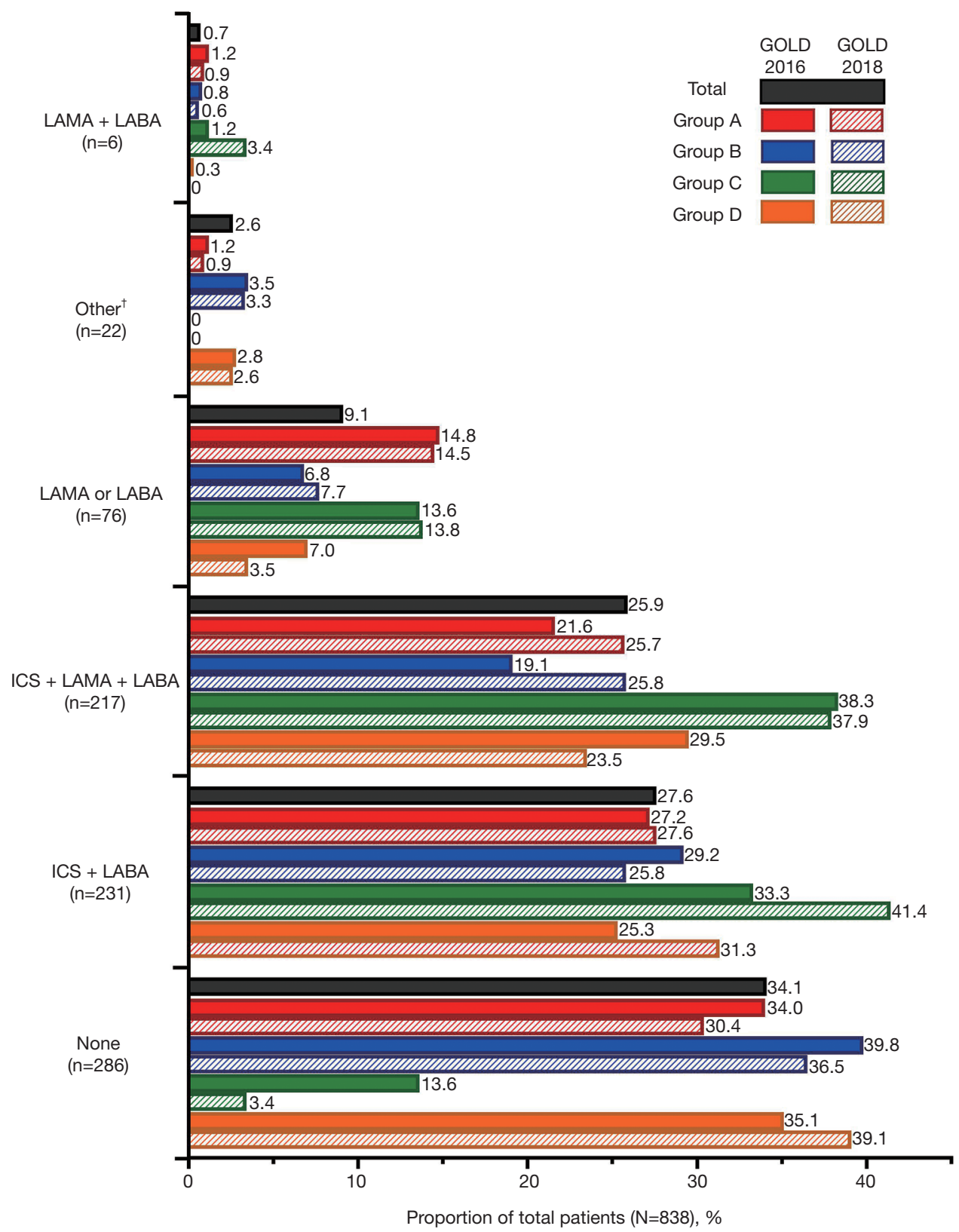

Figure 4 Proportion of patients receiving COPD inhaled therapies $(\mathrm{N}=838){ }^{\dagger}$, patients receiving $\mathrm{SABA}(\mathrm{n}=7)$, SAMA + SABA ( $\left.=2\right)$, and SAMA ( $\mathrm{n}=1)$ are grouped with "Other" $(\mathrm{n}=12)$ in the above figure due to small patient numbers in these categories. The types of medication included in the "Other" category $(\mathrm{n}=12)$ were not captured. COPD, chronic obstructive pulmonary disease; GOLD, Global Initiative for Chronic Obstructive Lung Disease; ICS, inhaled corticosteroid; LABA, long-acting $\beta_{2}$-agonist; LAMA, long-acting muscarinic antagonist; SABA, short-acting $\beta_{2}$-agonist; SAMA, short-acting muscarinic antagonist.

population, $\mathrm{n}=102$ ) were using it for $<15$ hours per day.

Of the total study population, $1.0 \%$ were on non-invasive ventilation support and none of the patients were reported to have undergone a surgical treatment for their disease.

\section{Demographic and clinical characteristics stratified according to COPD inbaled medications}

The majority of patients across all treatment groups had experienced no exacerbations in the previous year 


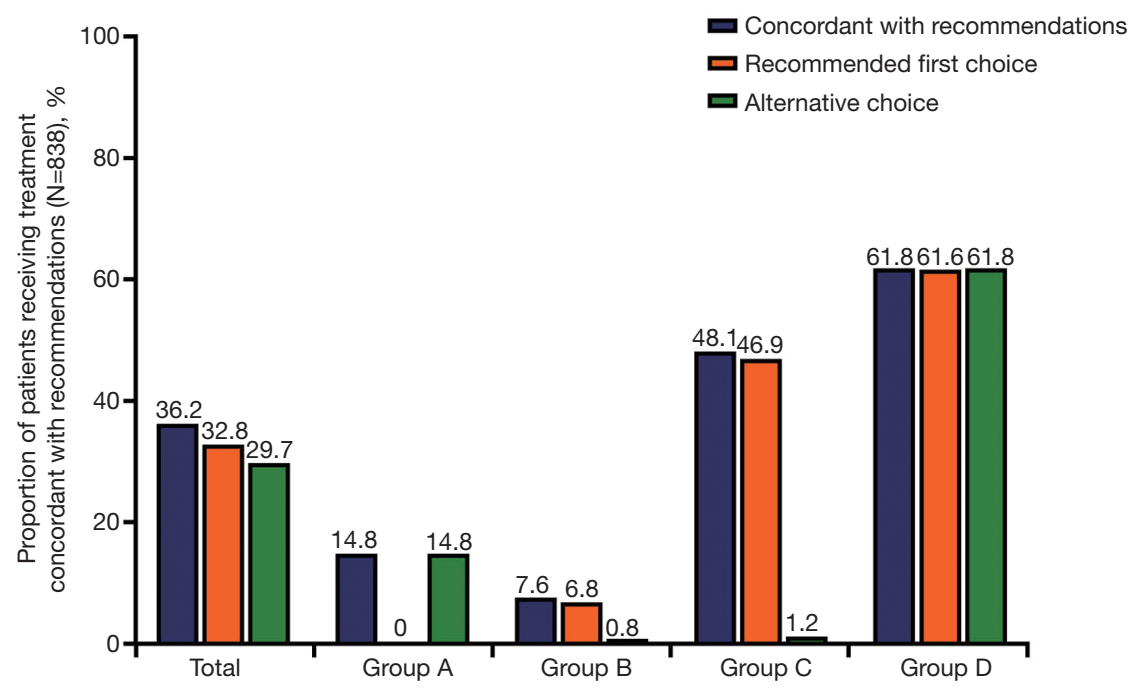

Figure 5 Proportion of patients receiving treatment concordant with treatment recommendations per GOLD 2016 (N=838). GOLD, Global Initiative for Chronic Obstructive Lung Disease.

(range, 66.7-81.8\%; Table S3). Patients receiving ICS + LABA combination therapy were the most likely to have experienced $\geq 1$ exacerbation requiring hospitalization or $\geq 2$ exacerbations in the prior year $[20.8 \%(n=48)]$ and patients receiving LAMA or LABA therapy were the least likely to have experienced $\geq 1$ exacerbation requiring hospitalization or $\geq 2$ exacerbations in the prior year $[10.5 \%$ $(\mathrm{n}=8)]$. Based on spirometry classification, $44.5 \%(\mathrm{n}=373)$ of all patients were classed as GOLD 2. Overall, $13.5 \%(n=113)$ of patients were classed as GOLD 4. This was similar across treatment groups, with the exception of the LAMA + LABA treatment group, in which no patients were classed as GOLD 4, although this could be explained by the low number of patients $(\mathrm{n}=6)$.

In patients not receiving any COPD treatment $(n=286)$, there was a slightly lower proportion of male patients compared with the total population [79.4\% $(\mathrm{n}=227)$ vs. $86.4 \%(\mathrm{n}=724)$, respectively] and a slightly higher proportion of never smokers $[28.3 \%(\mathrm{n}=81)$ vs. $21.5 \%$ $(\mathrm{n}=180)$, respectively]. A slightly higher proportion of patients not receiving any COPD treatment had no history of exacerbations in the previous year compared with the total population $[81.8 \%(\mathrm{n}=234)$ vs. $74.9 \%(\mathrm{n}=628)]$. However, the mean (SD) $\mathrm{FEV}_{1}$ in patients not receiving any COPD treatment was similar to that of the total population [1.44 L (0.6) vs. $1.39 \mathrm{~L}(0.6)$, respectively], as was the mean (SD) $\mathrm{FEV}_{1} / \mathrm{FVC}$ ratio $[0.51$ (0.11) vs. 0.49 (0.12), respectively] and the mean (SD) $\mathrm{FEV}_{1} \%$ predicted [54.7
(20.4) vs. 52.7 (19.4), respectively].

In patients with $\mathrm{mMRC}$ dyspnea grade $\geq 2$, most patients were either not receiving a current COPD treatment [37.3\% ( $\mathrm{n}=150 / 402)]$ or were receiving ICS + LAMA + LABA [29.4\% ( $\mathrm{n}=118 / 402)]$. The majority of patients with mMRC dyspnea grade <2 was also receiving no current COPD treatment $[31.2 \%(n=136 / 436)]$, with the second largest majority of patients receiving ICS + LABA [30.7\% $(\mathrm{n}=134 / 436)]$.

In patients with a GOLD 3 or 4 spirometry classification (i.e., those in GOLD Groups C or D according to GOLD 2016 criteria), most were receiving either ICS + LAMA + LABA [33.0\% (n=128/388)] or no current COPD treatment $[31.7 \%(\mathrm{n}=123 / 388)]$. In patients with a GOLD 1 or 2 spirometry classification (i.e., those in GOLD Groups A or B according to GOLD 2016 criteria), the most common therapy was no current COPD treatment [36.2\% ( $\mathrm{n}=163 / 450)]$, followed by ICS + LABA [31.1\% $(\mathrm{n}=140 / 450)]$.

\section{Discussion}

Our study described the distribution and clinical characteristics of patients with COPD in a Chinese cohort using GOLD 2016 and GOLD 2018 classifications. The distribution of COPD severity shifted so that the majority of patients were reclassified from a high-risk category per GOLD 2016 to a low-risk category per 
GOLD 2018. According to the GOLD 2016 criteria, the largest proportion of patients was in Group D (42.8\%), followed by Group B (28.2\%), while according to GOLD 2018 criteria, more patients were classified in Group B (57.3\%) and Group A (25.5\%). Overall, 35.3\% of patients ( $n=296 / 838$ ) were reclassified from Group C to Group A, or Group D to Group B. This change in distribution of disease classification was due to the amendment of the classification criteria in the GOLD 2018 report, which omitted the use of spirometry. Per GOLD 2016, the majority of highrisk patients (Groups C and D) had severe-to-very severe airflow limitation (GOLD 3 and GOLD 4), while there were no patients in the low-risk groups (Groups A and B) with severe-to-very severe airflow limitation (GOLD 3 and GOLD 4). However, per GOLD 2018, there was a marked increase in the proportion of patients in Groups A and B with GOLD 3 and GOLD 4 airflow limitation, indicating that some patients with severe-to-very severe airflow limitation were classified as low risk using the updated criteria, which did not consider spirometry.

The argument for eliminating the degree of airflow limitation (based on spirometric grades) from the GOLD ABCD classification system was that spirometry does not capture the heterogeneity of COPD, and does not directly correlate with disease severity (11). Airflow limitation is a clinically important trait that is both measurable and treatable, with opportunities for intervention to improve outcomes for individual patients (12). However, the data reported here suggest that classifying patients using the GOLD 2018 criteria, which do not consider airflow limitation, may cause under-recognition of disease severity, which may result in under-estimation of disease burden and reduced intensity of therapy in patients with COPD. This finding is consistent with several other studies comparing the distribution of patients in Groups A-D using the updated GOLD guidelines (13-19). Of particular relevance, a study in China investigated the distribution of patients with COPD in Groups A-D by GOLD 2017 criteria compared with GOLD 2014 criteria (14). Approximately one-third of patients who were originally classified into high-risk groups (Groups C and D) by GOLD 2014 were reclassified into low-risk groups (Groups A and B) by GOLD 2017. A greater proportion of patients were classified into Groups A and B by GOLD 2017 (50.4\%) compared with GOLD 2014 (27.0\%), with a corresponding decrease in the proportion of patients in Groups $\mathrm{C}$ and D (14). GOLD 2017 was the first GOLD classification to eliminate spirometry as a criterion for classification (8), while GOLD 2014 still included spirometry; therefore, this observation is broadly applicable to our analysis. Taken together with the results of our study, these data could suggest that, in Chinese patients with COPD, spirometry remains a useful and reliable objective tool for physicians to classify disease severity. Thus, it may be beneficial for local guideline committees to consider the value of spirometry as an assessment tool, alongside history of exacerbations, to ensure that the presence of treatable traits including airflow limitation are appropriately identified.

In the current study, there was a greater proportion of patients in the overall population with $\geq 1$ exacerbation requiring hospitalization in the previous 12 months versus those with one exacerbation not requiring hospitalization. However, this relationship has previously been shown to be inverted. In the ECLIPSE observational study (20), Hurst et al. showed that in patients with COPD, there was a rate of 0.22 exacerbations/patient/year requiring hospitalization compared with a rate of 0.41 exacerbations/patient/year requiring only corticosteroids and antibiotics, suggesting that exacerbations not requiring hospitalization were nearly twice as frequent as exacerbations requiring hospitalization. In contrast, this study found that the proportion of patients with exacerbations requiring hospitalization was nearly twice that of patients with exacerbations not requiring hospitalization ( $14.1 \%$ vs. $7.6 \%$, respectively). This discrepancy between different study populations may reflect under-reporting or under-recognition of exacerbations not requiring hospitalization in real-life practice compared with clinical trials. It is possible that it may also represent differences in healthcare systems between countries: the ECLIPSE study was conducted in a global cohort in centers in the United States, Canada, and across Europe, compared with the Chinese cohort in the present study. Speculatively, China may have a lower threshold for hospitalization compared with other countries, or more inclusive health insurance facilitating hospitalization. Additionally, the recognition and recording of exacerbations not requiring hospitalization depends on patients seeking medical assistance in order to be prescribed medications (corticosteroids and/or antibiotics); therefore, it is possible that failure of patients to seek medical intervention could lead to under-reporting of these exacerbations. This could also represent a difference between real-world clinical practice and clinical trials; for example, clinical trials may have more rigid guidelines about how exacerbations are recorded, while in this study, data were collected from realworld clinical practice (patient recall and medical records), 
and as such may not be as accurate as clinical trials due to inexact patient recall or under-reporting of exacerbations. These data do however represent real-world challenges, and under-reporting of all exacerbations (both those requiring and those not requiring hospitalization) is a known issue in real-world practice $(21,22)$. Because history of exacerbations is a key aspect in COPD disease classification, some patients may be erroneously considered low risk, which may have implications for management of their disease. Further exploration is required to ensure the accurate diagnosis and management of exacerbations not requiring hospitalization. An additional contributing factor to the high rates of hospitalization in this study population could be the high levels of patients in this study not receiving any COPD therapy: $35-40 \%$ of patients in Group D (by both GOLD 2016 and 2018) were not taking any COPD therapy.

Per GOLD 2016, the mean total CAT score of patients in Group A was 6.0 out of a maximum of 40.0, indicative of fewer COPD symptoms and a less severe impact of COPD on health status. However, $66.0 \%$ of these patients were receiving treatment, most commonly ICS + LABA or ICS + LAMA + LABA. Given that enrolled patients had a diagnosis of COPD for $\geq 1$ year, this could suggest that these therapies resulted in better control of symptoms and a reduction in exacerbations compared with other therapies. An alternative explanation for the low CAT score (representing a low impact of COPD symptoms on the health status of patients) is that the measurement of CAT score and mMRC dyspnea score is subjective, as they are based on patient self-assessment. Therefore, CAT score may vary according to patient population; for example, some patient populations may be more tolerant of symptoms than others, hence CAT score may not always fully reflect symptom burden. In this sample of patients with COPD in China, ICS-containing treatments were the dominant COPD inhaled maintenance medications, with $27.6 \%$ and $25.9 \%$ of total patients respectively receiving ICS + LABA and ICS + LAMA + LABA. Speculatively, this could be accounted for by an extensive availability of ICScontaining treatments in China, or widespread acceptance of the anti-inflammatory properties of ICS by Chinese physicians, leading to a high level of use. However, the GOLD 2021 report states that ICS is not suitable for all patients with COPD (1), citing repeated pneumonia events, blood eosinophil count $<100$ cells $/ \mu \mathrm{L}$, and history of mycobacterial infection as contraindications for ICS therapy. Additionally, the American Thoracic Society 2020 guidelines also propose that ICS should be withdrawn in patients receiving triple therapy who have had no exacerbations in the previous year (23). The possibility of ICS overuse in patients with COPD in China requires further investigation.

Of note, a large proportion of patients in this study were not receiving any COPD therapy (neither maintenance therapy nor rescue medication). When compared with the total population, a greater proportion of patients not receiving any COPD therapy experienced no exacerbations in the previous year; however, their mean $\mathrm{FEV}_{1}, \mathrm{FEV}_{1}$ / $\mathrm{FVC}$ ratio, and $\mathrm{FEV}_{1} \%$ predicted values were indicative of symptomatic disease, suggesting an unmet need in this population. The proportion of patients in this population not receiving any maintenance therapy may be representative of a wider problem of under-treatment of COPD in China. In a recent analysis of 25,011 patients in the China Kadoorie Biobank, only $9 \%$ of patients with COPD in China reported use of any medication in the last 7 days to alleviate symptoms and reduce the frequency and severity of exacerbations (24). Further investigation into the lack of use of maintenance therapy is required, as it may have implications on patient outcomes and healthcare resource use due to worsening of disease and risk of exacerbations. The reclassification of patients into lower risk groups (i.e., reclassification from Group C to A and Group D to B) may result in patients receiving ICS + LABA + LAMA being downgraded to dual bronchodilators. However, the effect of this step-down treatment in this patient population would require further study. For example, reclassification of patients from Group D to Group B may result in the step down of triple therapy (ICS + LABA + LAMA) to dual bronchodilators (LABA/ LAMA), due to the exacerbation risk being lower in Group B than Group D (1). On the other hand, the reclassification from Group C to Group A may result in treatment step down from LAMA to short-acting $\beta_{2}$-agonist/shortacting muscarinic antagonist (pro re nata). This may have important clinical implications for patients, especially those who under-report or do not effectively communicate their symptoms to healthcare professionals.

According to both the GOLD 2016 and GOLD 2018 classifications, the mean pack years for former and current smokers were highest in patients in Group D, reflecting the adverse impact of smoking. Smoking cessation remains the primary obstacle for the prevention of COPD in China. Secondary obstacles, including BMI and waistline measurement, did not appear to be major contributing factors for this population, with the majority of patients in the BMI 
category 18.5-23.9. Support with nutrition and smoking cessation should be provided to patients with COPD, with the goal of improving prognosis and quality of life.

A limitation of the present study was that the study population comprised outpatients assessed at selected tertiary hospitals, and therefore may not be representative of the entire population of patients with COPD in China. There are no general practitioner or respiratory specialist offices in China, which means that patients tend to visit tertiary hospitals for examinations, diagnoses, and treatment. The focus on tertiary care centers, therefore, might have resulted in a population sample with more severe disease than the general population of patients with COPD treated in primary care; alternatively, some patients with severe COPD might not have been able to attend hospital appointments, resulting in a study population with less severe disease. However, efforts were made to include a group of centers representative of the general population in China. Finally, certain variables were based on patients' recall and/or data collected from medical records; thus, there was the potential for recall bias.

Since the GOLD 2017 update that eliminated spirometry as a criterion for the $\mathrm{ABCD}$ categorization system, a number of further minor updates to the GOLD report have been published. In the GOLD 2021 revision (1), the main changes address key points regarding COVID-19 in the context of COPD including recommendations for remote follow-up during pandemic restrictions. Notably, the criteria for GOLD classification have not changed since the 2017 update, so these additional updates will not affect the present analyses.

\section{Conclusions}

In this Chinese cohort, COPD severity for the majority of patients shifted from a high-risk category (Group D) per GOLD 2016 to a low-risk category (Group B) per GOLD 2018. The elimination of spirometry as a criterion from the GOLD 2018 classification could result in underrecognition of disease severity, leading to a higher number of patients in the low-risk categories. The reclassification of patients to low-risk groups per GOLD 2018 (i.e., Group C to A or Group D to B) compared with GOLD 2016 may lead to a step down in treatment for these patients, which is likely to influence patient outcomes. The proportion of patients not receiving any COPD maintenance medication was high according to both classifications, reflecting a high level of under-treatment of COPD disease in this patient population. Further investigation is required to assess the implications of these findings on patient outcomes and to seek optimal solutions for disease management.

\section{Acknowledgments}

We would like to thank the patients and their families for participating in this study. We would also like to thank $\mathrm{Lu}$ $\mathrm{Zi}$ for support with statistical analyses and Sylvia Lu for support with protocol development, study site engagement, and providing background information.

Funding: This work was supported by GlaxoSmithKline (China) R\&D Company Limited (GlaxoSmithKline plc. study 207136) and the Ministry of Chinese Science and Technology National Key R\&D program (2018YFC1311900).

\section{Footnote}

Reporting Checklist: The authors have completed the STROBE reporting checklist. Available at https://dx.doi. org/10.21037/jtd-21-255

Data Sharing Statement: Available at https://dx.doi. org/10.21037/jtd-21-255

Conflicts of Interest: All authors have completed the ICMJE uniform disclosure form (available at https://dx.doi. org/10.21037/jtd-21-255). All authors declare that the present manuscript was supported by GlaxoSmithKline plc. in funding, medical writing, and article processing charges. WJ reports grant from GlaxoSmithKline (China) R\&D Company Limited (GlaxoSmithKline plc. study 207136) and the Ministry of Chinese Science and Technology National Key R\&D program (2018YFC1311900), outside the submitted work. JZ has participated in advisory boards and speakers' bureaus for AstraZeneca and Boehringer Ingelheim. At time of study conduct, YL and YW were employees of GlaxoSmithKline plc., reporting personal fees. Editorial support (in the form of writing assistance, collating author comments, assembling tables/figures, grammatical editing, and referencing) was provided by Varkha Agrawal, PhD, of Tata Consultancy Services (India), and Bonnie Nicholson, PhD, of Ashfield MedComms (Macclesfield, UK), an Ashfield Health company, and was funded by GlaxoSmithKline plc.

Etbical Statement: The authors are accountable for all aspects of the work in ensuring that questions related 
to the accuracy or integrity of any part of the work are appropriately investigated and resolved. This study was conducted in accordance with the Declaration of Helsinki (as revised in 2013) and Good Clinical Practice. The study was approved by the Ethics Committee of scientific research project review in the First Affiliated Hospital of Guangzhou Medical University (approval no. 2018 K-19) and written informed consent was obtained for all participants. The study protocol and patient information were reviewed and approved by the appropriate Independent Ethics Committee, which was to be constituted in accordance with all applicable regulatory requirements. GlaxoSmithKline plc. provided the investigator with relevant documents and/or data that were needed for Independent Ethics Committee review and approval of the study.

Open Access Statement: This is an Open Access article distributed in accordance with the Creative Commons Attribution-NonCommercial-NoDerivs 4.0 International License (CC BY-NC-ND 4.0), which permits the noncommercial replication and distribution of the article with the strict proviso that no changes or edits are made and the original work is properly cited (including links to both the formal publication through the relevant DOI and the license). See: https://creativecommons.org/licenses/by-nc-nd/4.0/.

\section{References}

1. Global Initiative for Chronic Obstructive Pulmonary Disease (GOLD), Global strategy for the diagnosis, management and prevention of chronic obstructive pulmonary disease (2021 report). Accessed May 2021. Available online: https://goldcopd.org/wp-content/ uploads/2020/11/GOLD-REPORT-2021-v1.1-25Nov20_ WMV.pdf

2. GBD 2017 Causes of Death Collaborators. Global, regional, and national age-sex-specific mortality for 282 causes of death in 195 countries and territories, 1980-2017: a systematic analysis for the Global Burden of Disease Study 2017. Lancet 2018;392:1736-88.

3. Fang L, Gao P, Bao H, et al. Chronic obstructive pulmonary disease in China: a nationwide prevalence study. Lancet Respir Med 2018;6:421-30.

4. GBD 2016 Causes of Death Collaborators. Global, regional, and national age-sex specific mortality for 264 causes of death, 1980-2016: a systematic analysis for the Global Burden of Disease Study 2016. Lancet 2017;390:1151-210. Erratum in: Lancet 2017;390:e38.
5. Pauwels RA, Buist AS, Calverley PM, et al. Global strategy for the diagnosis, management, and prevention of chronic obstructive pulmonary disease. NHLBI/WHO Global Initiative for Chronic Obstructive Lung Disease (GOLD) Workshop summary. Am J Respir Crit Care Med 2001;163:1256-76.

6. Global Initiative for Chronic Obstructive Pulmonary Disease (GOLD). Global strategy for the diagnosis, management and prevention of chronic obstructive pulmonary disease (2011 report).

7. Gruffydd-Jones K. GOLD guidelines 2011: what are the implications for primary care? Prim Care Respir J 2012;21:437-41.

8. Global Initiative for Chronic Obstructive Pulmonary Disease (GOLD). Global strategy for the diagnosis, management and prevention of chronic obstructive pulmonary disease (2017 REPORT). Accessed May 2021. Available online: https://goldcopd.org/wp-content/ uploads/2017/02/wms-GOLD-2017-FINAL.pdf

9. Global Initiative for Chronic Obstructive Pulmonary Disease (GOLD). Global strategy for the diagnosis, management and prevention of chronic obstructive pulmonary disease (2016 report).

10. Global Initiative for Chronic Obstructive Pulmonary Disease (GOLD). Global strategy for the diagnosis, management and prevention of chronic obstructive pulmonary disease (2018 report). Accessed May 2021. Available online: https://goldcopd.org/wp-content/ uploads/2017/11/GOLD-2018-v6.0-FINAL-revised-20Nov_WMS.pdf

11. Agusti A, Calverley PM, Celli B, et al. Characterisation of COPD heterogeneity in the ECLIPSE cohort. Respir Res 2010;11:122.

12. McDonald VM, Fingleton J, Agusti A, et al. Treatable traits: a new paradigm for 21 st century management of chronic airway diseases: Treatable Traits Down Under International Workshop report. Eur Respir J 2019;53:1802058.

13. Cabrera López C, Casanova Macario C, Marín Trigo JM, et al. Comparison of the 2017 and 2015 Global Initiative for Chronic Obstructive Lung Disease Reports. Impact on Grouping and Outcomes. Am J Respir Crit Care Med 2018;197:463-9.

14. Cui Y, Dai Z, Luo L, et al. Classification and treatment of chronic obstructive pulmonary disease outpatients in China according to the Global Initiative for Chronic Obstructive Lung Disease (GOLD) 2017: comparison with GOLD 2014. J Thorac Dis 2019;11:1303-15. 
15. Faner R, Noell G, Badia JR, et al. Distribution, temporal stability and association with all-cause mortality of the 2017 GOLD groups in the ECLIPSE cohort. Respir Med 2018;141:14-9.

16. Hsieh MJ, Huang SY, Yang TM, et al. The impact of 2011 and 2017 Global Initiative for Chronic Obstructive Pulmonary Disease (GOLD) guidelines on allocation and pharmacological management of patients with COPD in Taiwan: Taiwan Obstructive Lung Disease (TOLD) study. Int J Chron Obstruct Pulmon Dis 2018;13:2949-59.

17. Sun L, Chen Y, Wu R, et al. Changes in definition lead to changes in the clinical characteristics across COPD categories according to GOLD 2017: a national crosssectional survey in China. Int J Chron Obstruct Pulmon Dis 2017;12:3095-102.

18. Tan WC, Bourbeau J, Aaron SD, et al. Global Initiative for Chronic Obstructive Lung Disease 2017 Classification and Lung Function Decline in Chronic Obstructive Pulmonary Disease. Am J Respir Crit Care Med 2018;197:670-3.

19. Tudoric N, Koblizek V, Miravitlles M, et al. GOLD 2017 on the way to a phenotypic approach? Analysis from the Phenotypes of COPD in Central and Eastern Europe

Cite this article as: Jian W, Zeng $\mathrm{H}$, Zhang $\mathrm{X}$, Yun $\mathrm{C}, \mathrm{Xu} Z$, Chen Y, Shi G, Wang Y, Li Y, Zheng J. Clinical characteristics of patients with chronic obstructive pulmonary disease assessed using GOLD 2016 and GOLD 2018 classifications: a crosssectional study in China. J Thorac Dis 2021;13(10):5701-5716. doi: $10.21037 /$ jtd-21-255
(POPE) Cohort. Eur Respir J 2017;49:1602518.

20. Hurst JR, Vestbo J, Anzueto A, et al. Susceptibility to exacerbation in chronic obstructive pulmonary disease. $\mathrm{N}$ Engl J Med 2010;363:1128-38.

21. Langsetmo L, Platt RW, Ernst P, et al. Underreporting exacerbation of chronic obstructive pulmonary disease in a longitudinal cohort. Am J Respir Crit Care Med 2008;177:396-401.

22. Wilkinson TM, Donaldson GC, Hurst JR, et al. Early therapy improves outcomes of exacerbations of chronic obstructive pulmonary disease. Am J Respir Crit Care Med 2004;169:1298-303.

23. Nici L, Mammen MJ, Charbek E, et al. Pharmacologic Management of Chronic Obstructive Pulmonary Disease. An Official American Thoracic Society Clinical Practice Guideline. Am J Respir Crit Care Med 2020;201:e56-69.

24. Kurmi OP, Davis KJ, Hubert Lam KB, et al. Patterns and management of chronic obstructive pulmonary disease in urban and rural China: a community-based survey of 25000 adults across 10 regions. BMJ Open Respir Res 2018;5:e000267. 
Table S1 Demographics and clinical characteristics of patients reclassified to a new group per GOLD $2018 \mathrm{criteria}(\mathrm{n}=296)$

\begin{tabular}{|c|c|c|c|}
\hline Characteristic & Total $^{\dagger}(\mathrm{n}=296)$ & Group $C$ to $A^{\ddagger}(n=52)$ & Group $D$ to $B^{\S}(n=244)$ \\
\hline Age, years, mean (SD) & $65.2(8.0)$ & $64.4(8.1)$ & $65.3(7.9)$ \\
\hline \multicolumn{4}{|l|}{ Age group, n (\%) } \\
\hline$<65$ years & $132(44.6)$ & $31(59.6)$ & $101(41.4)$ \\
\hline$\geq 65$ years & $164(55.4)$ & $21(40.4)$ & $143(58.6)$ \\
\hline \multicolumn{4}{|l|}{ Gender, n (\%) } \\
\hline Male & $265(89.5)$ & $44(84.6)$ & $221(90.6)$ \\
\hline \multicolumn{4}{|l|}{$\mathrm{BMI}, \mathrm{kg} / \mathrm{m}^{2}$} \\
\hline Mean (SD) & $22.1(3.4)$ & $22.5(3.0)$ & $22.0(3.5)$ \\
\hline \multicolumn{4}{|l|}{ BMI group, n (\%) } \\
\hline$<18.5$ & $39(13.2)$ & $4(7.7)$ & $35(14.3)$ \\
\hline $18.5-23.9$ & $174(58.8)$ & $30(57.7)$ & $144(59.0)$ \\
\hline $24-27.9$ & $70(23.6)$ & $15(28.8)$ & $55(22.5)$ \\
\hline$\geq 28$ & $13(4.4)$ & $3(5.8)$ & $10(4.1)$ \\
\hline \multicolumn{4}{|l|}{ Waistline measurement, $\mathrm{cm}$} \\
\hline $\mathrm{n}$ & 296 & 52 & 244 \\
\hline Mean (SD) & $85.2(11.3)$ & $82.6(10.7)$ & $85.7(11.4)$ \\
\hline \multicolumn{4}{|l|}{ Smoking status, $\mathrm{n}(\%)$} \\
\hline Never smoker & $53(17.9)$ & $11(21.2)$ & $42(17.2)$ \\
\hline Former smoker & $175(59.1)$ & $29(55.8)$ & $146(59.8)$ \\
\hline Current smoker & $68(23.0)$ & $12(23.1)$ & $56(23.0)$ \\
\hline \multicolumn{4}{|c|}{ Pack-years for former and current smokers ${ }^{\pi}$} \\
\hline $\mathrm{n}$ & 243 & 41 & 202 \\
\hline Mean (SD) & $38.6(25.2)$ & $33.8(21.6)$ & $39.6(25.8)$ \\
\hline \multicolumn{4}{|l|}{ mMRC dyspnea grade, $\mathrm{n}(\%)$} \\
\hline 0 & $17(5.7)$ & $10(19.2)$ & $7(2.9)$ \\
\hline 1 & $103(34.8)$ & $27(51.9)$ & $76(31.1)$ \\
\hline 2 & $108(36.5)$ & $13(25.0)$ & $95(38.9)$ \\
\hline 3 & $63(21.3)$ & $2(3.8)$ & $61(25.0)$ \\
\hline 4 & $5(1.7)$ & 0 & $5(2.0)$ \\
\hline CAT total score, mean (SD) & $17.1(7.7)$ & $5.9(2.5)$ & $19.5(6.1)$ \\
\hline \multicolumn{4}{|c|}{ CAT total score category, $\mathrm{n}(\%)$} \\
\hline $0-<10$ & $52(17.6)$ & $52(100)$ & 0 \\
\hline $10-<20$ & $122(41.2)$ & 0 & $122(50.0)$ \\
\hline $20-<30$ & $111(37.5)$ & 0 & $111(45.5)$ \\
\hline $30-\leq 40$ & $11(3.7)$ & 0 & $11(4.5)$ \\
\hline
\end{tabular}

Table S1 (continued) 
Table S1 (continued)

\begin{tabular}{|c|c|c|c|}
\hline Characteristic & Total $^{\dagger}(n=296)$ & Group $C$ to $A^{\ddagger}(n=52)$ & Group $D$ to $B^{\S}(n=244)$ \\
\hline \multicolumn{4}{|l|}{ Exacerbation status, $\mathrm{n}(\%)^{\dagger \dagger}$} \\
\hline No exacerbations & $271(91.6)$ & $44(84.6)$ & $227(93.0)$ \\
\hline 1 exacerbation (not requiring hospitalization) & $25(8.4)$ & $8(15.4)$ & $17(7.0)$ \\
\hline$\geq 1$ exacerbation requiring hospitalization & 0 & 0 & 0 \\
\hline$\geq 2$ exacerbations & 0 & 0 & 0 \\
\hline $\begin{array}{l}\geq 1 \text { exacerbation requiring hospitalization or } \\
\geq 2 \text { exacerbations }\end{array}$ & 0 & 0 & 0 \\
\hline \multicolumn{4}{|l|}{ Spirometry classification, $\mathrm{n}(\%)^{\ddagger \ddagger}$} \\
\hline GOLD 1 & 0 & 0 & 0 \\
\hline GOLD 2 & 0 & 0 & 0 \\
\hline GOLD 3 & $209(70.6)$ & $50(96.2)$ & $159(65.2)$ \\
\hline GOLD 4 & $87(29.4)$ & $2(3.8)$ & $5(34.8)$ \\
\hline $\mathrm{FEV}_{1}, \mathrm{~L}$, mean $(\mathrm{SD})$ & $0.96(0.3)$ & $1.08(0.2)$ & $0.94(0.3)$ \\
\hline $\mathrm{FEV}_{1} / \mathrm{FVC}$ ratio, mean (SD) & $0.40(0.1)$ & $0.41(0.1)$ & $0.40(0.1)$ \\
\hline $\mathrm{FEV}_{1} \%$ predicted, mean (SD) & $35.82(9.2)$ & $40.91(6.3)$ & $34.73(9.4)$ \\
\hline
\end{tabular}

${ }^{\dagger}$, Group C per GOLD 2016 reclassified to Group A per GOLD 2018 + Group D per GOLD 2016 reclassified to Group B per GOLD 2018.

${ }^{\ddagger}$, Group C per GOLD 2016 reclassified to Group A per GOLD 2018. ${ }^{\S}$, Group D per GOLD 2016 reclassified to Group B per GOLD 2018.

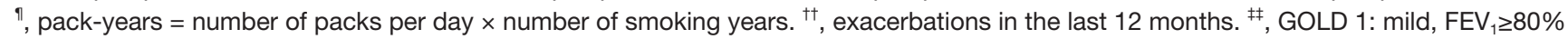
predicted; GOLD 2: moderate, $50 \% \leq \mathrm{FEV}_{1}<80 \%$ predicted; GOLD 3: severe, $30 \% \leq \mathrm{FEV}_{1}<50 \%$ predicted; GOLD 4: very severe, $\mathrm{FEV}{ }_{1}<30 \%$ predicted. Spirometry was only considered in the GOLD 2016 classification, not in the GOLD 2018 classification. BMI, body mass index; CAT, COPD Assessment Test; COPD, chronic obstructive pulmonary disease; FEV 1 , forced expiratory volume in 1 second; FVC, forced vital capacity; GOLD, Global Initiative for Chronic Obstructive Lung Disease; mMRC, modified Medical Research Council; SD, standard deviation. 
Table S2 Proportion of patients receiving treatment and concordance with treatment recommendations per GOLD 2016 (N=838)

\begin{tabular}{|c|c|c|c|c|c|c|c|c|c|}
\hline & \multirow{2}{*}{ Total } & \multicolumn{4}{|c|}{ GOLD 2016} & \multicolumn{4}{|c|}{ GOLD 2018} \\
\hline & & Group A & Group B & Group C & Group D & Group A & Group B & Group C & Group D \\
\hline Patients, n (\%) & $838(100.0)$ & $162(19.3)$ & $236(28.2)$ & $81(9.7)$ & $359(42.8)$ & $214(25.5)$ & $480(57.3)$ & $29(3.5)$ & $115(13.7)$ \\
\hline $\begin{array}{l}\text { Patients receiving treatment } \\
\text { concordant with GOLD } 2016 \\
\text { recommendations, n (\%) }\end{array}$ & $303(36.2)$ & $24(14.8)$ & $18(7.6)$ & $39(48.1)$ & $222(61.8)$ & N/A & N/A & N/A & N/A \\
\hline $\begin{array}{l}\text { Patients receiving treatment } \\
\text { concordant with the GOLD } \\
2016 \text { recommended first } \\
\text { choice, } \mathrm{n}(\%)\end{array}$ & $275(32.8)$ & 0 & $16(6.8)$ & $38(46.9)$ & $221(61.6)$ & N/A & N/A & N/A & $\mathrm{N} / \mathrm{A}$ \\
\hline $\begin{array}{l}\text { Patients receiving treatment } \\
\text { concordant with the GOLD } \\
2016 \text { alternative choice, } n(\%)\end{array}$ & 249 (29.7) & $24(14.8)$ & $2(0.8)$ & $1(1.2)$ & $222(61.8)$ & N/A & N/A & N/A & $\mathrm{N} / \mathrm{A}$ \\
\hline \multicolumn{10}{|l|}{ COPD inhaled medications, $\mathrm{n}(\%)$} \\
\hline None & $286(34.1)$ & $55(34.0)$ & $94(39.8)$ & $11(13.6)$ & $126(35.1)$ & $65(30.4)$ & $175(36.5)$ & $1(3.4)$ & $45(39.1)$ \\
\hline ICS + LABA & $231(27.6)$ & $44(27.2)$ & $69(29.2)$ & 27 (33.3) & $91(25.3)$ & 59 (27.6) & $124(25.8)$ & $12(41.4)$ & $36(31.3)$ \\
\hline ICS + LAMA + LABA & 217 (25.9) & $35(21.6)$ & $45(19.1)$ & $31(38.3)$ & $106(29.5)$ & $55(25.7)$ & $124(25.8)$ & $11(37.9)$ & $27(23.5)$ \\
\hline LAMA & $75(8.9)$ & $24(14.8)$ & $16(6.8)$ & $11(13.6)$ & $24(6.7)$ & $31(14.5)$ & $36(7.5)$ & $4(13.8)$ & $4(3.5)$ \\
\hline Other ${ }^{\dagger}$ & $12(1.4)$ & $2(1.2)$ & $5(2.1)$ & 0 & $5(1.4)$ & $2(0.9)$ & $8(1.7)$ & 0 & $2(1.7)$ \\
\hline SABA & $7(0.8)$ & 0 & $5(2.1)$ & 0 & $2(0.6)$ & 0 & $7(1.5)$ & 0 & 0 \\
\hline LAMA + LABA & $6(0.7)$ & $2(1.2)$ & $2(0.8)$ & $1(1.2)$ & $1(0.3)$ & $2(0.9)$ & $3(0.6)$ & $1(3.4)$ & 0 \\
\hline SAMA + SABA & $2(0.2)$ & 0 & 0 & 0 & $2(0.6)$ & 0 & $2(0.4)$ & 0 & 0 \\
\hline LABA & $1(0.1)$ & 0 & 0 & 0 & $1(0.3)$ & 0 & $1(0.2)$ & 0 & 0 \\
\hline SAMA & $1(0.1)$ & 0 & 0 & 0 & $1(0.3)$ & 0 & 0 & 0 & $1(0.9)$ \\
\hline
\end{tabular}

${ }^{\dagger}$, the types of medication included in the "Other" category were not captured. COPD, chronic obstructive pulmonary disease; GOLD, Global Initiative for Chronic Obstructive Lung Disease; ICS, inhaled corticosteroid; LABA, long-acting $\beta_{2}$-agonist; LAMA, long-acting muscarinic antagonist; N/A, not applicable; SABA, short-acting $\beta_{2}$-agonist; SAMA, short-acting muscarinic antagonist. 
Table S3 Patient demographics and clinical characteristics by COPD inhaled medications (N=838)

\begin{tabular}{|c|c|c|c|c|c|c|c|}
\hline Characteristic & $\begin{array}{c}\text { Total } \\
(\mathrm{N}=838)\end{array}$ & $\begin{array}{l}\text { LAMA or LABA } \\
\qquad(n=76)\end{array}$ & $\begin{array}{c}\text { LAMA + LABA } \\
(n=6)\end{array}$ & $\begin{array}{c}\text { ICS + LABA } \\
(n=231)\end{array}$ & $\begin{array}{c}\text { ICS + LAMA + LABA } \\
(n=217)\end{array}$ & $\begin{array}{l}\text { Other }^{\dagger} \\
(n=22)\end{array}$ & $\begin{array}{l}\text { No current COPD } \\
\text { treatment }(n=286)\end{array}$ \\
\hline Age, years, mean (SD) & $65.7(8.6)$ & $66.6(7.2)$ & $59.3(8.8)$ & $66.6(8.5)$ & $66.8(8.3)$ & $65.1(6.5)$ & $63.9(9.0)$ \\
\hline \multicolumn{8}{|l|}{ Age group, n (\%) } \\
\hline$<65$ years & 347 (41.4) & 25 (32.9) & $4(66.7)$ & 103 (44.6) & $84(38.7)$ & $8(36.4)$ & $123(43.0)$ \\
\hline \multicolumn{8}{|l|}{ Gender, n (\%) } \\
\hline Male & 724 (86.4) & $67(88.2)$ & $5(83.3)$ & 206 (89.2) & $200(92.2)$ & $19(86.4)$ & $227(79.4)$ \\
\hline \multicolumn{8}{|l|}{$\mathrm{BMI}, \mathrm{kg} / \mathrm{m}^{2}$} \\
\hline $\mathrm{n}$ & 836 & 76 & 6 & 231 & 216 & 21 & 286 \\
\hline Mean (SD) & $23.1(3.6)$ & $22.4(3.3)$ & $23.6(1.0)$ & $23.2(3.7)$ & $22.7(3.6)$ & $22.3(3.5)$ & $23.5(3.7)$ \\
\hline \multicolumn{8}{|l|}{ BMI group, n (\%) } \\
\hline$<18.5$ & $78(9.3)$ & $9(11.8)$ & 0 & $18(7.8)$ & $26(12.0)$ & $2(9.5)$ & $23(8.0)$ \\
\hline $18.5-23.9$ & 434 (51.9) & $44(57.9)$ & $4(66.7)$ & $125(54.1)$ & $110(50.9)$ & $14(66.7)$ & 137 (47.9) \\
\hline $24.0-27.9$ & $250(29.9)$ & $21(27.6)$ & $2(33.3)$ & $68(29.4)$ & $64(29.6)$ & $3(14.3)$ & $92(32.2)$ \\
\hline$\geq 28$ & $74(8.9)$ & $2(2.6)$ & 0 & $20(8.7)$ & $16(7.4)$ & $2(9.5)$ & $34(11.9)$ \\
\hline Missing & $2(0.2)$ & 0 & 0 & 0 & $1(0.4)$ & $1(4.5)$ & 0 \\
\hline \multicolumn{8}{|c|}{ Waistline measurement, $\mathrm{cm}$} \\
\hline $\mathrm{n}$ & 834 & 76 & 6 & 229 & 216 & 21 & 286 \\
\hline Mean (SD) & $86.5(10.3)$ & $84.0(11.3)$ & $90.5(11.9)$ & $87.04(10.1)$ & $87.8(11.5)$ & $85.3(11.3)$ & $85.8(8.9)$ \\
\hline \multicolumn{8}{|l|}{ Smoking status, n (\%) } \\
\hline Former smoker & $449(53.6)$ & 45 (59.2) & $3(50.0)$ & $129(55.8)$ & $124(57.1)$ & $14(63.6)$ & 134 (46.9) \\
\hline Current smoker & 209 (24.9) & $19(25.0)$ & $2(33.3)$ & $58(25.1)$ & $54(24.9)$ & $5(22.7)$ & $71(24.8)$ \\
\hline \multicolumn{8}{|c|}{ Pack-years for former and current smokers ${ }^{\ddagger}$} \\
\hline $\mathrm{n}$ & 658 & 64 & 5 & 187 & 178 & 19 & 205 \\
\hline Mean (SD) & $39.05(25.8)$ & $41.04(28.8)$ & $54.0(19.5)$ & $37.4(24.4)$ & $41.9(29.4)$ & $35.7(17.3)$ & $37.5(23.2)$ \\
\hline \multicolumn{8}{|c|}{ mMRC dyspnea grade ${ }^{\S}, \mathrm{n}(\%)$} \\
\hline 0 & $120(14.3)$ & $12(15.8)$ & $2(33.3)$ & $42(18.2)$ & $18(8.3)$ & $2(9.1)$ & $44(15.4)$ \\
\hline 1 & $316(37.7)$ & $38(50.0)$ & $3(50.0)$ & $92(39.8)$ & $81(37.3)$ & $10(45.5)$ & $92(32.2)$ \\
\hline 2 & $269(32.1)$ & $22(28.9)$ & $1(16.7)$ & $68(29.4)$ & $83(38.2)$ & $4(18.2)$ & $91(31.8)$ \\
\hline 3 & $120(14.3)$ & $3(3.9)$ & 0 & $25(10.8)$ & $30(13.8)$ & $4(18.2)$ & $58(20.3)$ \\
\hline 4 & $13(1.6)$ & $1(1.3)$ & 0 & $4(1.7)$ & $5(2.3)$ & $2(9.1)$ & $1(0.3)$ \\
\hline $\begin{array}{l}\text { CAT total score, } \\
\text { mean (SD) }\end{array}$ & $15.0(8.0)$ & $11.5(6.7)$ & $11.2(4.9)$ & $14.4(7.9)$ & $14.8(8.0)$ & $17.7(7.0)$ & $16.4(8.0)$ \\
\hline \multicolumn{8}{|c|}{ CAT total score category, n (\%) } \\
\hline $0-<10$ & $243(29.0)$ & $35(46.1)$ & $3(50.0)$ & $71(30.7)$ & $66(30.4)$ & $2(9.1)$ & $66(23.1)$ \\
\hline $10-<20$ & $345(41.2)$ & $30(39.5)$ & $3(50.0)$ & $96(41.6)$ & $86(39.6)$ & $11(50.0)$ & $119(41.6)$ \\
\hline $20-<30$ & $221(26.4)$ & $11(14.5)$ & 0 & $59(25.5)$ & $55(25.3)$ & $9(40.9)$ & $87(30.4)$ \\
\hline $30-\leq 40$ & $29(3.5)$ & 0 & 0 & $5(2.2)$ & $10(4.6)$ & 0 & $14(4.9)$ \\
\hline
\end{tabular}

Table S3 (continued) 
Table S3 (continued)

\begin{tabular}{|c|c|c|c|c|c|c|c|}
\hline Characteristic & $\begin{array}{c}\text { Total } \\
(\mathrm{N}=838)\end{array}$ & $\begin{array}{l}\text { LAMA or LABA } \\
\quad(n=76)\end{array}$ & $\begin{array}{l}\text { LAMA + LABA } \\
\quad(n=6)\end{array}$ & $\begin{array}{c}\text { ICS + LABA } \\
(n=231)\end{array}$ & $\begin{array}{c}\text { ICS + LAMA + LABA } \\
(\mathrm{n}=217)\end{array}$ & $\begin{array}{l}\text { Other }^{\dagger} \\
(n=22)\end{array}$ & $\begin{array}{l}\text { No current COPD } \\
\text { treatment }(n=286)\end{array}$ \\
\hline \multicolumn{8}{|c|}{ Exacerbation status, $\mathrm{n}(\%)^{\pi}$} \\
\hline No exacerbations & $628(74.9)$ & $59(77.6)$ & $4(66.7)$ & $157(68.0)$ & $158(72.8)$ & $16(72.7)$ & $234(81.8)$ \\
\hline $\begin{array}{l}1 \text { exacerbation } \\
\text { (not requiring } \\
\text { hospitalization) }\end{array}$ & $64(7.6)$ & $9(11.8)$ & $1(16.7)$ & $26(11.3)$ & $21(9.7)$ & $3(13.6)$ & $4(1.4)$ \\
\hline $\begin{array}{l}\geq 1 \text { exacerbation } \\
\text { requiring } \\
\text { hospitalization }\end{array}$ & $118(14.1)$ & $5(6.6)$ & $1(16.7)$ & $33(14.3)$ & $31(14.3)$ & $3(13.6)$ & $45(15.7)$ \\
\hline$\geq 2$ exacerbations & $46(5.5)$ & $4(5.3)$ & 0 & $22(9.5)$ & $14(6.5)$ & $1(4.5)$ & $5(1.7)$ \\
\hline $\begin{array}{l}\geq 1 \text { exacerbation } \\
\text { requiring } \\
\text { hospitalization or } \\
\geq 2 \text { exacerbations }\end{array}$ & $144(17.2)$ & $8(10.5)$ & $1(16.7)$ & $48(20.8)$ & $38(17.5)$ & $3(13.6)$ & $46(16.1)$ \\
\hline \multicolumn{8}{|c|}{ Spirometry classification, $\mathrm{n}(\%)$} \\
\hline GOLD 1 & $77(9.2)$ & $5(6.6)$ & $1(16.7)$ & $26(11.3)$ & $8(3.7)$ & $2(9.1)$ & $35(12.2)$ \\
\hline GOLD 2 & $373(44.5)$ & $37(48.7)$ & $3(50.0)$ & $114(49.4)$ & $81(37.3)$ & $10(45.5)$ & $128(44.8)$ \\
\hline GOLD 3 & $275(32.8)$ & $24(31.6)$ & $2(33.3)$ & $63(27.3)$ & $92(42.4)$ & $7(31.8)$ & $87(30.4)$ \\
\hline GOLD 4 & $113(13.5)$ & $10(13.2)$ & $0(0.0)$ & $28(12.1)$ & $36(16.6)$ & $3(13.6)$ & $36(12.6)$ \\
\hline $\mathrm{FEV}_{1}$, L, mean $(\mathrm{SD})$ & $1.39(0.6)$ & $1.35(0.5)$ & $1.88(0.8)$ & $1.45(0.6)$ & $1.26(0.5)$ & $1.45(0.6)$ & $1.44(0.6)$ \\
\hline $\begin{array}{l}\mathrm{FEV}_{1} / \mathrm{FVC} \text { ratio, } \\
\text { mean }(\mathrm{SD})\end{array}$ & $0.49(0.12)$ & $0.48(0.12)$ & $0.53(0.12)$ & $0.50(0.12)$ & $0.46(0.11)$ & $0.46(0.14)$ & $0.51(0.11)$ \\
\hline $\begin{array}{l}\mathrm{FEV}_{1} \% \text { predicted, } \\
\text { mean (SD) }\end{array}$ & $52.7(19.4)$ & $52.1(17.4)$ & $60.5(19.7)$ & $55.2(19.9)$ & $47.4(17.3)$ & $53.1(19.2)$ & $54.7(20.4)$ \\
\hline \multicolumn{8}{|l|}{ GOLD 2016, n (\%) } \\
\hline Group A & $162(19.3)$ & $24(31.6)$ & $2(33.3)$ & $44(19.0)$ & $35(16.1)$ & $2(9.1)$ & 55 (19.2) \\
\hline Group B & $236(28.2)$ & $16(21.1)$ & $2(33.3)$ & 69 (29.9) & $45(20.7)$ & $10(45.5)$ & 94 (32.9) \\
\hline Group C & $81(9.7)$ & $11(14.5)$ & $1(16.7)$ & $27(11.7)$ & $31(14.3)$ & $0(0.0)$ & $11(3.8)$ \\
\hline Group D & $359(42.8)$ & 25 (32.9) & $1(16.7)$ & $91(39.4)$ & $106(48.8)$ & $10(45.5)$ & $126(44.1)$ \\
\hline \multicolumn{8}{|l|}{ GOLD 2018, n (\%) } \\
\hline Group A & $214(25.5)$ & $31(40.8)$ & $2(33.3)$ & $59(25.5)$ & $55(25.3)$ & $2(9.1)$ & $65(22.7)$ \\
\hline Group B & $480(57.3)$ & $37(48.7)$ & $3(50.0)$ & $124(53.7)$ & $124(57.1)$ & $17(77.3)$ & $175(61.2)$ \\
\hline Group C & $29(3.5)$ & $4(5.3)$ & $1(16.7)$ & $12(5.2)$ & $11(5.1)$ & $0(0.0)$ & $1(0.3)$ \\
\hline Group D & $115(13.7)$ & $4(5.3)$ & $0(0.0)$ & $36(15.6)$ & $27(12.4)$ & $3(13.6)$ & $45(15.7)$ \\
\hline
\end{tabular}

${ }^{\dagger}$, patients receiving SABA $(n=7)$, SAMA + SABA $(n=2)$, and SAMA $(n=1)$ are grouped with "Other" $(n=12)$ in the above due to small patient numbers in these categories. The types of medication included in the "Other" category $(n=12)$ were not captured. ${ }^{\ddagger}$, pack-years $=$ number of packs per day $\times$ number of smoking years. ${ }^{\S}$, Grade 0 , breathless only with strenuous exercise; grade 1, breathless when hurrying on the level or walking on a slight hill; grade 2, walks slower than people of the same age on the level because of breathlessness or has to stop when walking at own pace on the level; grade 3, stops for breath after walking $100 \mathrm{~m}$ or after a few minutes on the level; grade 4, too breathless to leave the house or breathless when dressing or undressing. ", exacerbations in the last 12 months. BMI, body mass index; CAT, COPD Assessment Test; COPD, chronic obstructive pulmonary disease; FEV ${ }_{1}$, forced expiratory volume in 1 second; FVC, forced vital capacity; GOLD, Global Initiative for Chronic Obstructive Lung Disease; ICS, inhaled corticosteroid; LABA, long-acting $\beta_{2}$-agonist; LAMA, long-acting muscarinic antagonist; mMRC, modified Medical Research Council; SABA, short-acting $\beta_{2}$-agonist; SAMA, short-acting muscarinic antagonist; SD, standard deviation. 
GOLD 2016

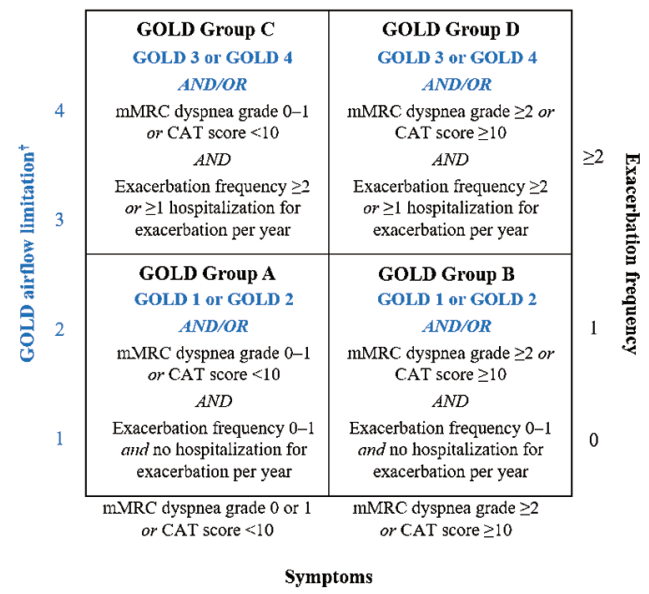

GOLD 2018

\begin{tabular}{|c|c|}
\hline GOLD Group C & GOLD Group D \\
\hline mMRC dyspnea grade $0-1$ & mMRC dyspnea grade $\geq 2$ or \\
\hline $\begin{array}{c}\text { OPCAI scole }<10 \\
A N D\end{array}$ & $\begin{array}{c}\text { CAT score } \geq 10 \\
A N D\end{array}$ \\
\hline $\begin{array}{l}\text { Exacerbation frequency } \geq 2 \\
\text { or } \geq 1 \text { hospitalization for } \\
\text { exacerbation per year }\end{array}$ & $\begin{array}{l}\text { Exacerbation frequency } \geq 2 \\
\text { or } \geq 1 \text { hospitalization for } \\
\text { exacerbation per year }\end{array}$ \\
\hline GOLD Group A & GOLD Group B \\
\hline $\begin{array}{c}\text { mMRC dyspnea grade } 0-1 \\
\text { or CAT score }<10 \\
A N D\end{array}$ & $\begin{array}{c}\text { mMRC dyspnea grade } \geq 2 \text { or } \\
\text { CAT score } \geq 10 \\
A N D\end{array}$ \\
\hline $\begin{array}{l}\text { Exacerbation frequency } 0-1 \\
\text { and no lospitalization for } \\
\text { exacerbation per year }\end{array}$ & $\begin{array}{l}\text { Exacerbation frequency } 0-1 \\
\text { and no hospitalization for } \\
\text { exacerbation per year }\end{array}$ \\
\hline $\begin{array}{l}\text { mMRC dyspnea grade } 0 \text { or } 1 \\
\text { or } \text { CAT score }<10\end{array}$ & $\begin{array}{l}\text { mMRC dyspnea grade } \geq 2 \\
\text { or CAT score } \geq 10\end{array}$ \\
\hline
\end{tabular}

Figure S1 ABCD classification criteria for GOLD 2016 and GOLD 2018. ${ }^{\dagger}$, GOLD 1: mild, $\mathrm{FEV}_{1} \geq 80 \%$ predicted; GOLD 2: moderate, $50 \% \leq \mathrm{FEV}_{1}<80 \%$ predicted; GOLD 3: severe, $30 \% \leq \mathrm{FEV}_{1}<50 \%$ predicted; GOLD 4 : very severe, $\mathrm{FEV}_{1}<30 \%$ predicted. Only considered for GOLD 2016 criteria. CAT, COPD Assessment Test; COPD, chronic obstructive pulmonary disease; $\mathrm{FEV}_{1}$, forced expiratory volume in 1 second; GOLD, Global Initiative for Chronic Obstructive Lung Disease; mMRC, modified Medical Research Council. 